\title{
Nanopore structures of isolated kerogen and bulk shale in Bakken Formation
}

\author{
Kouqi Liu ${ }^{\text {a,*}, ~ M e h d i ~ O s t a d h a s s a n ~}{ }^{\text {a,*}}$, Jie Zou ${ }^{b}$, Thomas Gentzis ${ }^{c}$, Reza Rezaee ${ }^{b}$, Bailey \\ Bubach $^{\mathrm{a}}$, Humberto Carvajal-Ortiz ${ }^{\mathrm{c}}$ \\ ${ }^{a}$ Department of Petroleum Engineering, University of North Dakota, Grand Forks, ND 58202 \\ b Department of Petroleum Engineering, Curtin University, Perth, Australia, 6151

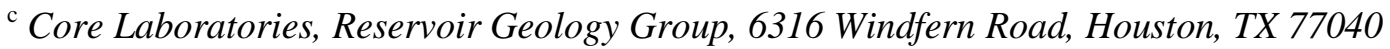 \\ *Corresponding author, email address: kouqi.liu@ ndus.edu; mehdi.ostadhassan@engr.und.edu;
}

\begin{abstract}
Pores that exist within the organic matter can affect the total pore system of bulk shale samples and, as a result, need to be studied and analyzed carefully. In this study, samples from the Bakken Formation, in conjunction with the kerogen that was isolated from them, were studied and compared through a set of analytical techniques: X-ray diffraction (XRD), Rock-Eval pyrolysis, Fourier Transform infrared spectroscopy (FTIR), and gas adsorption $\left(\mathrm{CO}_{2}\right.$ and $\left.\mathrm{N}_{2}\right)$. The results can be summarized as follows: 1) quartz and clays are two major minerals in the Bakken samples; 2) the samples have rich organic matter content with TOC greater than $10 \mathrm{wt} \%$; 3) kerogen is marine type II; 4) gas adsorption showed that isolated kerogen compared to the bulk sample has larger micropore volume and surface area, meso- and macropore volume, and Brunauer-Emmett-Teller (BET) surface area; 5) deconvolution of pore size distribution (PSD) curves demonstrated that pores in the isolated kerogen could be separated into five distinct clusters, whereas bulk shale samples exhibited one additional pore cluster with an average pore size of $4 \mathrm{~nm}$ hosted in the minerals. The comparison of PSD curves obtained from isolated kerogen and bulk shale samples proved that most of the micropores in the shale are hosted within the organic matter while the mesopores with a size ranging between 2 and 10nm are mainly hosted by minerals. The overall results demonstrated that organic matter-hosted pores make a significant contribution to the total porosity of the Bakken shale samples.
\end{abstract}

Keywords: Bakken shale; isolated kerogen; FTIR; gas adsorption; heterogeneity

\section{Introduction}

Characterizing pore structures of unconventional reservoirs, such as shale oil and gas from nanoto macroscale, has attracted the interest of many researchers [1-6]. It has been found that different properties of pores such as size distribution (PSD) could influence the storage capacity and 
permeability of these rock types [3, 7-8]. In addition, by determining the pore type, quantity and distribution, reservoir performance after an enhanced oil recovery (EOR) operation could be evaluated. Based on the recommendations by the International Union of Pure and Applied Chemistry (IUPAC) [9], pores can be divided into three groups from the size perspective: micropores $(<2 \mathrm{~nm})$, mesopores $(2-50 \mathrm{~nm})$ and macropores $(>50 \mathrm{~nm})$. While considering the type, three groups of pores can be identified: 1) interparticle pores; 2) mineral intraparticle pores and 3) intraparticle pores hosted by the organic matter [3].

It is well understood that unconventional self-sourced shale reservoirs contain various concentration levels of organic matter in their source rock adjacent to the reservoir rock. Several studies on shale gas formations have pointed out that the presence of organic matter can significantly affect the properties of the rock such as the porosity [7-8, 10], gas content [11], methane sorption capacity [12-14] and mechanical properties [15-16]. Organic-hosted pores are mainly measured to be less than a micrometer and found to play a significant role in the pore network of shale gas formations [2]. Also, these pores are dominant contributors to the total porosity and hydrocarbon storage capacity in shale gas formations compared to the pores within the matrix [8]. Therefore, understanding the level of the contribution of organic matter hosted pores, in the overall network of pores, in shale reservoirs can notably enhance any estimated petrophysical properties of such rock types.

Considering what was mentioned above, a few researchers have studied the impact of organic matter on the total pore system in shale gas reservoirs with two different approaches: 1) extracting the kerogen and studying the pore structures of the isolated kerogen [1, 17] or 2) removing the organic matter from the shale samples and evaluating the pore structures of the remaining minerals [10]. However, to our best knowledge, there is not any published research that investigates the influence of organic matter and the pores associated with it, on the total porosity of shale oil formations, particularly for the Bakken Shale which is the focus of this study. Since, the level of thermal maturity in shale gas and shale oil formations are entirely different, the impact of organic hosted pores [18] in the overall pore network should be considered and reported. We believe this study can elevate our understanding on the impact that organic matter at various level can have on the pore network of organic rich shale rocks. 
Different techniques, such as imaging methods [2, 5, 18-23], gas adsorption [18, 24-26] and mercury injection [27] have been applied to study the pore structures of shale formations. Through imaging methods, such as field emission scanning electron microscopy (FESEM), one can observe both organic and the inorganic pores directly. However, the resolution limitations in the equipment (only pores larger than $9 \mathrm{~nm}$ can be detected) and the spatial restriction of the examined area can reduce the accuracy in quantifying and evaluating organic pore structures [5]. To carry out this analysis, gas adsorption which can characterize micropores ( $\mathrm{CO}_{2}$ adsorption) and mesomacropores ( $\mathrm{N}_{2}$ adsorption) has been a prevalent analytical method. Although the advantages in improving the resolution of measurement, pore information that is derived from gas adsorption cannot distinguish between organic matter hosted pores and mineral matrix pores [1].

In this study, we attempted to further our knowledge of the impact of organic matter on the overall pore structures and pore network in shale oil formations. For this purpose, we collected a few samples from the Bakken Formation in North Dakota, USA, and analyzed the pores using the gas adsorption method, on both bulk shale and on kerogen extracted from the same samples. We were able to quantify the difference in pore size distribution in these two sets of specimens and clarify the role of organic matter on the pore structure and network of bulk shale samples. Additional analytical techniques, such as FTIR spectroscopy, was acquired to provide us with molecular information and chemical functional groups of the samples studied.

\section{Samples and Methods}

\subsection{Samples}

The Bakken Formation is an organic-rich, mudstone and sandstone unit, located in the Williston Basin in both USA and Canada (Fig. 1). Based on the lithology, the Bakken Formation is divided into three different members: Upper, Middle, and Lower Bakken. The Upper and Lower Bakken are dark marine shale with high TOC content which is the source rock for the reservoir while Middle Bakken which is composed of mixed carbonates and fine-grained clastics is the mian production zone [28]. In this study, four samples from two separate wells from the Bakken

Formation were collected and prepared for various analyses, as explained later. To analyze the pore structure of organic matter independently from rock matrix, kerogen was isolated/extracted from the mineral matrix following the process outlined in the flowchart in Fig. 2. 


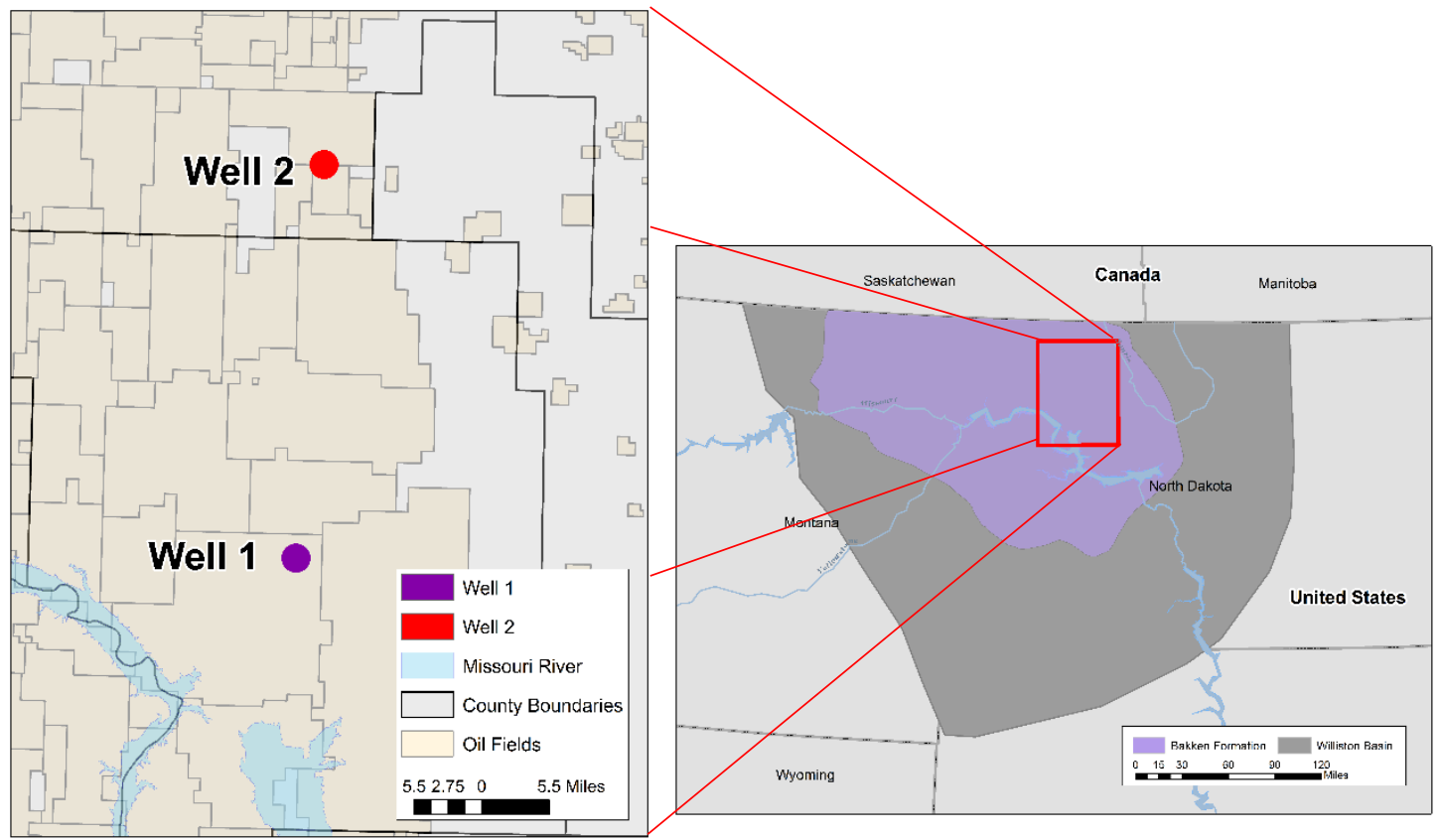

Fig. 1. Map of the Williston Basin and the extent of the Bakken Formation in the United Statesthe samples are taken from the wells marked on the map.

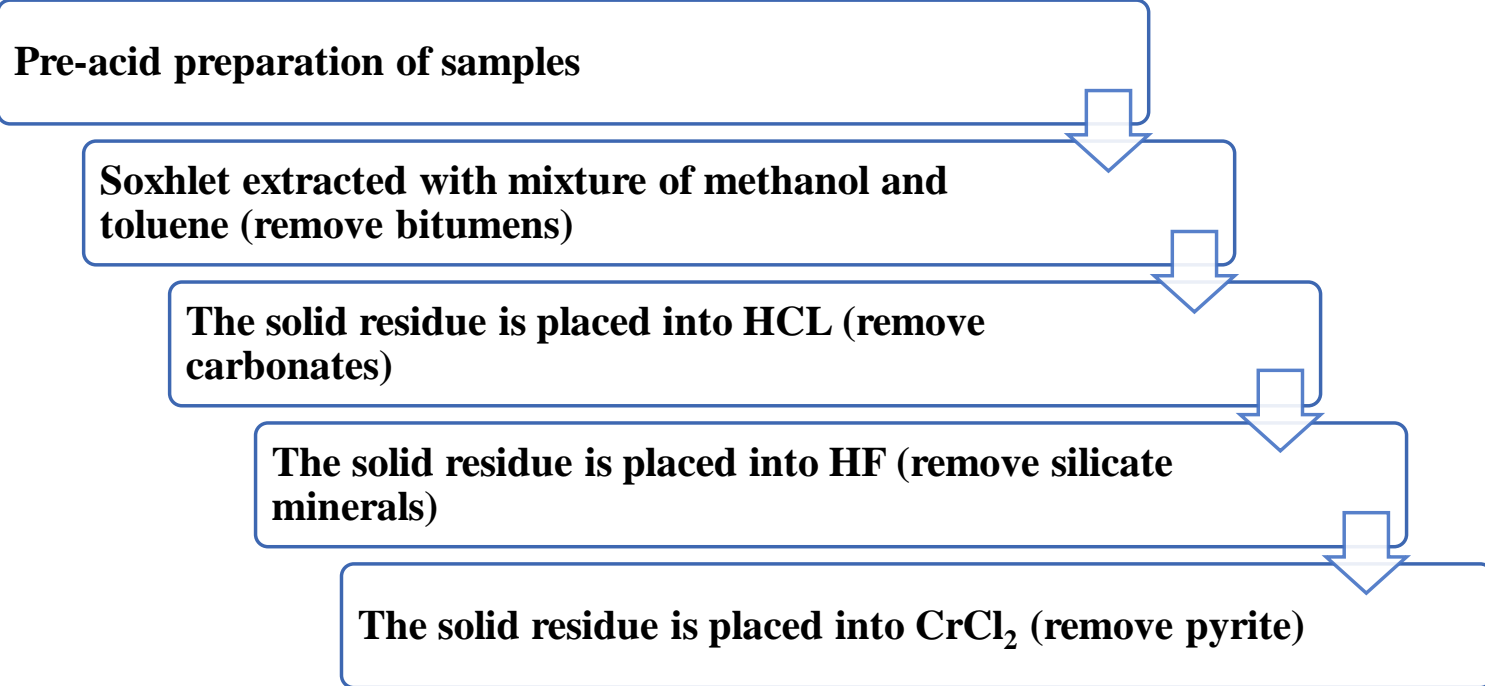

Fig. 2. The workflow of organic matter isolation process from mineral matrix [29].

\subsection{Mineralogy and organic petrography}

Bulk shale samples were crushed to less than a 650-mesh size and then placed into the Bruker D8 Advance X-ray diffractometer to obtain the mineralogical compositions of the samples. The diffractometer uses CoKa-radiation produced at $40 \mathrm{kv}$ and $44 \mathrm{~mA}$. The scanning measurements 
were performed at the rate of $2^{\circ}$ per minute in the range of 3-90 [5]. The quantitative analysis of the mineral compositions was determined by calculating and integrating the major peaks.

Rock-Eval pyrolysis was used to quantify the total organic carbon (TOC) content and hydrocarbon generating potential of the Bakken Shale samples. Approximately $30 \mathrm{mg}$ of each sample were used and analyzed by the Shale Play method proposed by the IFPEN [30]. The three-step temperature program (pyrogram) can be summarized as: the initial temperature was $100^{\circ} \mathrm{C}$, which was then increased to $200^{\circ} \mathrm{C}$ at a rate of $25^{\circ} \mathrm{C} / \mathrm{min}$ and held constant for 3 minutes. In the next step, the temperature was increased to $350^{\circ} \mathrm{C}$ at a rate of $25^{\circ} \mathrm{C} / \mathrm{min}$ and kept the same for 3 minutes. Finally, the temperature was raised to $650^{\circ} \mathrm{C}$ at a rate of $25^{\circ} \mathrm{C} / \mathrm{min}$ (Fig. 3) [30]. The maturity index was calculated using the following equation [31]:

$$
V_{R o}(\%)=0.018 \times T_{\max }-7.16
$$

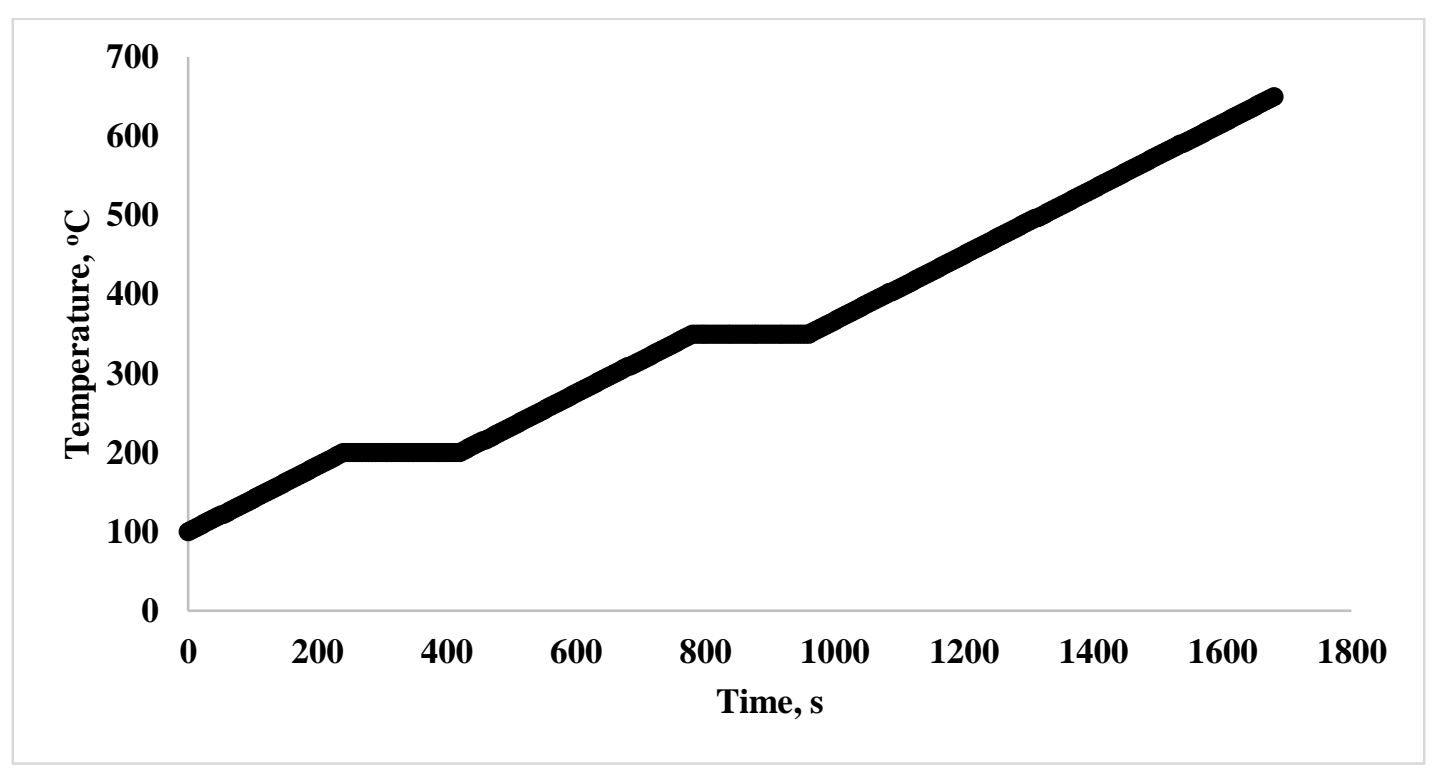

Fig. 3. The temperature program of the shale play method used in this study.

\subsection{FTIR analysis}

Fourier transform infrared (FTIR) spectroscopy involves the use of light to obtain the infrared spectrum of various type of materials in order to identify the presence of organic, polymeric, and in some cases, inorganic compounds. A Perkin Elmer Spectrum 400 was the equipment used for this purpose on both bulk shale and on the corresponding extracted kerogen. After the background noise is collected and subtracted from the main spectra, the FTIR spectrum of the samples is generated to show the unique chemical bonds, functional groups and molecular structures of the 
organic matter. The potassium bromide $(\mathrm{KBr})$ pellet method was used to acquire the IR spectra of finely ground samples. The homogenous powdered mixture was pressed (under vacuum) into a clear pellet at 10 tons $/ \mathrm{cm}^{2}$ for 10 minutes and placed in the equipment for FTIR testing. For more detailed information regarding sample preparation and spectral collection of FTIR, the reader is referred to Craddock et al. (2015) [32].

\subsection{Gas adsorption}

Prior to gas adsorption measurement, the samples (both the bulk shale and isolated kerogen) were degassed for at least 8 hours at $110^{\circ} \mathrm{C}$ to remove moisture and volatiles that may exist in the pores. Low-pressure nitrogen was measured on a Micromeritics® Tristar II apparatus at $77 \mathrm{~K}$ while carbon dioxide adsorption was performed a Micromeritics@ Tristar II plus apparatus at 273K. Gas adsorption volume was measured over the relative equilibrium adsorption pressure $\left(\mathrm{P} / \mathrm{P}_{0}\right)$ range of 0.01-0.99, where $\mathrm{P}$ is the gas vapour pressure in the system and $\mathrm{P}_{0}$ is the saturation pressure of nitrogen [18]. To calculate the pore size distribution (PSD) from the nitrogen adsorption, the density functional theory (DFT) molecular model was applied to the data [33]. Accordingly, the non-local density functional theory was employed to quantify the pore size distributions (PSD) curves of $\mathrm{CO}_{2}$ adsorption measured data [34-35].

\subsection{Multifractal analysis}

In order to understand the self-similarities in gas adsorption data (PSD curves) through the multifractal theory, the box-counting method was applied to the measurements, which is assigning a set of different boxes with length $\varepsilon$ to cover the PSD curves. The detailed procedure about how to calculate the multifractal behaviors of Bakken shale using gas adsorption is proposed by Liu et al., 2018 [36]. To apply this theory, relative pressure $\left(P / P_{0}\right)$ was taken as the length $\varepsilon$. In this method, one can label each of these boxes by index $i$. Therefore, $N(\varepsilon)$ indicates the total number of boxes needed to cover the interval understudy in the PSD curves from gas adsorption measurements. Consequently, the section of the $i$ th box of size $\varepsilon$ can be shown as $u_{i}(\varepsilon)$ [36-37]. Hereafter, the probability mass function for the $i$ th box can be calculated using the following equation:

$p_{i}(\varepsilon)=N_{i}(\varepsilon) / N_{T}$ 
Where, $N_{i}(\varepsilon)$ is the volume of adsorbed nitrogen for the $i$ th box and $N_{T}$ is the total volume of gas that is adsorbed in the pores. $P_{i}(\varepsilon)$ can also be defined by an exponential function of the following form for each box as:

$P_{i}(\varepsilon) \sim \varepsilon^{\alpha_{i}}$

When the box sizes get closer to 0 , then $\alpha_{i}$ which is the singularity exponent of the system, approaches infinity as $\varepsilon$ gets closer to 0 [38-39]. This exponent explains the level of singularities in the multi-fractal analysis. For multifractally distributed properties of intervals of size $\varepsilon, N(\varepsilon)$ increases when $\varepsilon$ decreases following a power law function of the form:

$N_{\alpha}(\varepsilon) \sim \varepsilon^{-f(\alpha)}$

where $N_{\alpha}(\varepsilon)$ is the number of boxes for which the probability mass function of the $i$ th box, $P_{i}(\varepsilon)$, has singularity strength between $\alpha$ and $\alpha+d \alpha$. Then, $f(\alpha)$ represents the spectrum of the fractal dimensions that characterize the abundance in the set of $\alpha$ singularity. Subsequently, $\alpha(q)$ and $f(\alpha)$ can be calculated based on the equations that are proposed by Chhabra and Jensen (1989) [40]:

$$
\begin{aligned}
& \alpha(q) \propto\left[\sum_{i=1}^{N(\varepsilon)}\left(u_{i}(q, \varepsilon) \times \ln p_{i}(\varepsilon)\right)\right] / \ln (\varepsilon) \\
& f(\alpha) \propto\left[\sum_{i=1}^{N(\varepsilon)}\left(u_{i}(q, \varepsilon) \times \ln u_{i}(q, \varepsilon)\right)\right] / \ln (\varepsilon)
\end{aligned}
$$

where

$$
u_{i}(q, \varepsilon)=\frac{p_{i}(\varepsilon)^{q}}{\sum_{i=1}^{N(\varepsilon)} p_{i}(\varepsilon)^{q}}
$$

Here, $q$ is the exponent expressing the fractal properties in different scales of the object. In this study, $\alpha$ and $f(\alpha)$ were calculated through a linear regression using Eq. 5 and Eq. 6 with $q$ varying from -10 to 10 for successive unit steps. $\alpha_{q \max }$ or $\alpha_{\max }$ in this study refers to $\alpha-10$ which represents the fluctuations of maximum probability $\left(\alpha_{\max }\right)$. Whereas $\alpha_{q \min }$ or $\alpha_{\min }$ corresponds to $\alpha_{10}$ which illustrate the fluctuations of the minimum probability $\left(\alpha_{\mathrm{min}}\right)$. The extension of the singularity length $(\Delta \alpha)$ which is defined as $\alpha_{\max }-\alpha_{\min }$ could reveal the heterogeneity of the probability. 
For multifractal applications, a probability distribution function can be defined as:

$$
u(q, \varepsilon)=\sum_{i=1}^{N(\varepsilon)} P_{i}(\varepsilon)^{q} \sim \varepsilon^{\tau(q)}
$$

Where $\tau_{q}$ is the mass scaling function of order $q$ which is:

$$
\tau(q)=\lim _{\varepsilon \rightarrow 0}\left[\ln \sum_{i} P_{i}(\varepsilon)^{q} / \ln (1 / \varepsilon)\right]
$$

then, the generalized dimension $\left(D_{q}\right)$ can be expressed as:

$$
D_{q}=\tau(q) /(q-1)
$$

While for $q=1, D_{q}$ can be written as:

$$
D_{1}=\lim _{\varepsilon \rightarrow 0} \sum_{i=1}^{N(\varepsilon)}\left(P_{i}(\varepsilon) \ln P_{i}(\varepsilon)\right) / \ln (\varepsilon)
$$

\section{Results and discussions}

\subsection{Mineral compositions and organic geochemistry}

Mineral compositions of the samples obtained from XRD analysis are summarized in Table 1. Quartz and clays (mainly illite) are major mineral constituents of the samples. Sample 2 has the highest clay mineral content while sample 3 has the least. Fig. 4 is the pyrogram of Sample 1 that was tested by Rock-Eval pyrolysis using the Shale Play method. This method generates the following parameters: Sh0 (thermo-vaporizable light hydrocarbons, C1-C15); Sh1 (medium-heavy oil or thermo-vaporizable hydrocarbons, C15-C40), and Sh2, (cracking of the remaining heavy hydrocarbons, NSO compounds, and/or kerogen). This specific pyrolysis process would allow us for a better understanding of the composition of the hydrocarbons generated by the samples upon heating [30]. Table 2 shows that the shale samples are rich in organic matter, with TOC varying from $11.07 \mathrm{wt} \%$ to $20.17 \mathrm{wt} \%$. The equivalent vitrinite reflectance values show that the organic

\begin{tabular}{|c|c|c|c|c|c|}
\hline Samples & Quartz & Pyrite & Feldspar & Dolomite & Clays \\
\hline
\end{tabular}
matter is in the early oil window. The plot of Sh2 versus TOC, shown in Fig. 5, illustrates that kerogen in these samples belongs to type II, which is oil- prone marine.

Table 1 Mineral compositions of the samples (in wt\%) 


\begin{tabular}{lccccc}
\hline Sample 1 & 70.30 & 3.15 & 7.70 & 0.00 & 18.81 \\
\hline Sample 2 & 54.30 & 8.07 & 0.00 & 8.80 & 28.60 \\
\hline Sample 3 & 66.90 & 2.44 & 14.40 & 0.00 & 16.20 \\
\hline Sample 4 & 70.00 & 2.35 & 5.50 & 0.00 & 22.20 \\
\hline
\end{tabular}

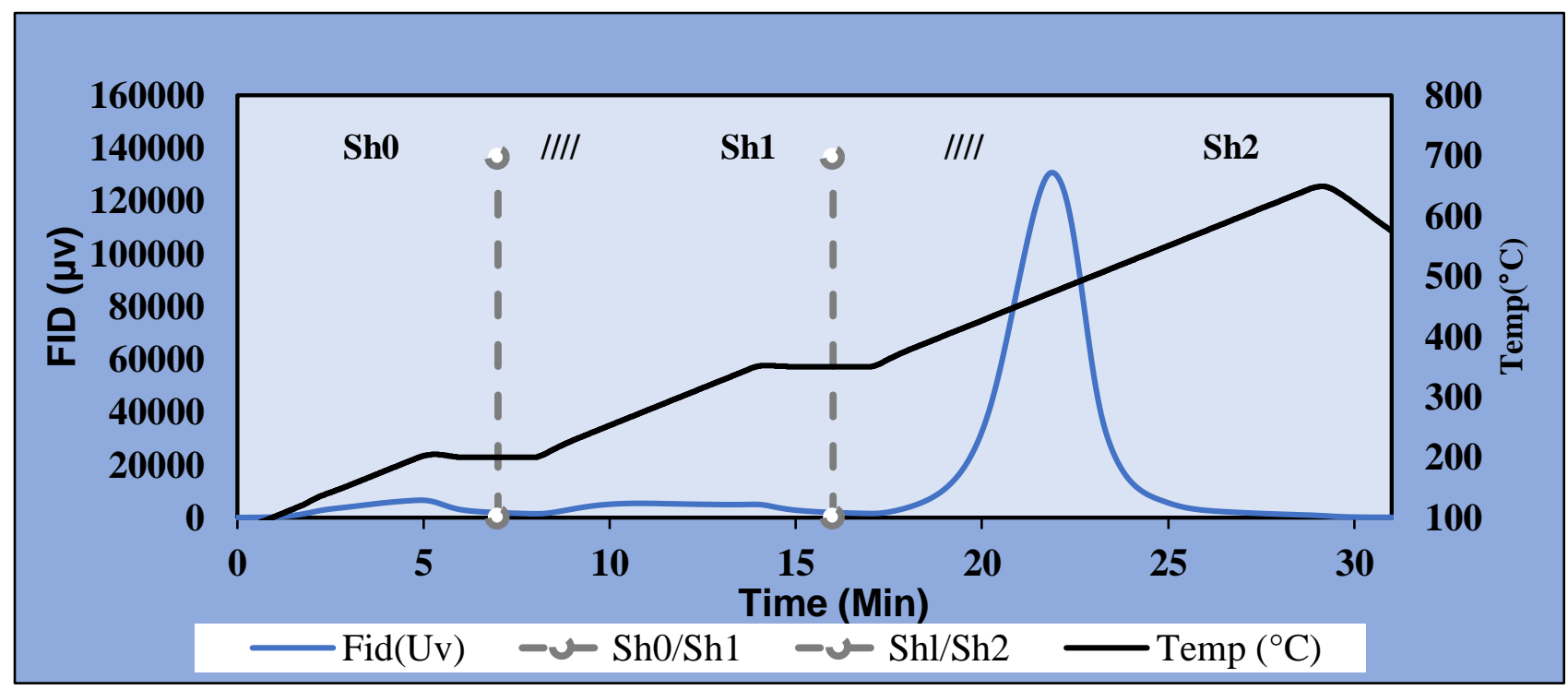

Fig. 4. Rock-Eval pyrogram of Sample 1 using shale play method.

Table 2 Geochemical analysis results of the samples obtained from Rock Eval pyrolysis.

\begin{tabular}{cccccccc}
\hline Samples & $\begin{array}{c}\text { TOC } \\
\mathbf{w t} \%\end{array}$ & $\begin{array}{c}\text { Tmax } \\
{ }^{\circ} \mathbf{C}\end{array}$ & $\begin{array}{c}\text { HI } \\
(\text { Sh2x100/TOC) }\end{array}$ & $\begin{array}{c}\text { OI } \\
(\text { S3x100/TOC) }\end{array}$ & $\begin{array}{c}\text { TPIs } \\
\text { Oil/(Oil+Sh2) }\end{array}$ & $\begin{array}{c}\text { Oil in Rock } \\
\text { bbl oil/ac-ft }\end{array}$ & $\begin{array}{c}\text { VRo-Eq } \\
(\%)\end{array}$ \\
\hline Sample 1 & 14.19 & 429 & 513.39 & 2.96 & 0.14 & 294.15 & 0.56 \\
\hline Sample 2 & 20.17 & 429 & 555.88 & 1.64 & 0.13 & 399.64 & 0.56 \\
\hline Sample 3 & 11.07 & 433 & 479.13 & 2.08 & 0.19 & 296.34 & 0.63 \\
\hline Sample 4 & 12.22 & 433 & 464.16 & 1.72 & 0.19 & 329.07 & 0.63 \\
\hline
\end{tabular}

Note: HI is Hydrogen Index (Sh2x100/TOC), OI is Oxygen Index (S3x100/TOC), Oil in rock (Oil) refers to (Sh0+Sh1 (hydrocarbon content)) and TPIs refers to the shale reservoir Production Index $((\mathrm{Sh} 0+\mathrm{Sh} 1) /(\mathrm{Sh} 0+\mathrm{Sh} 1+\mathrm{Sh} 2))$. 


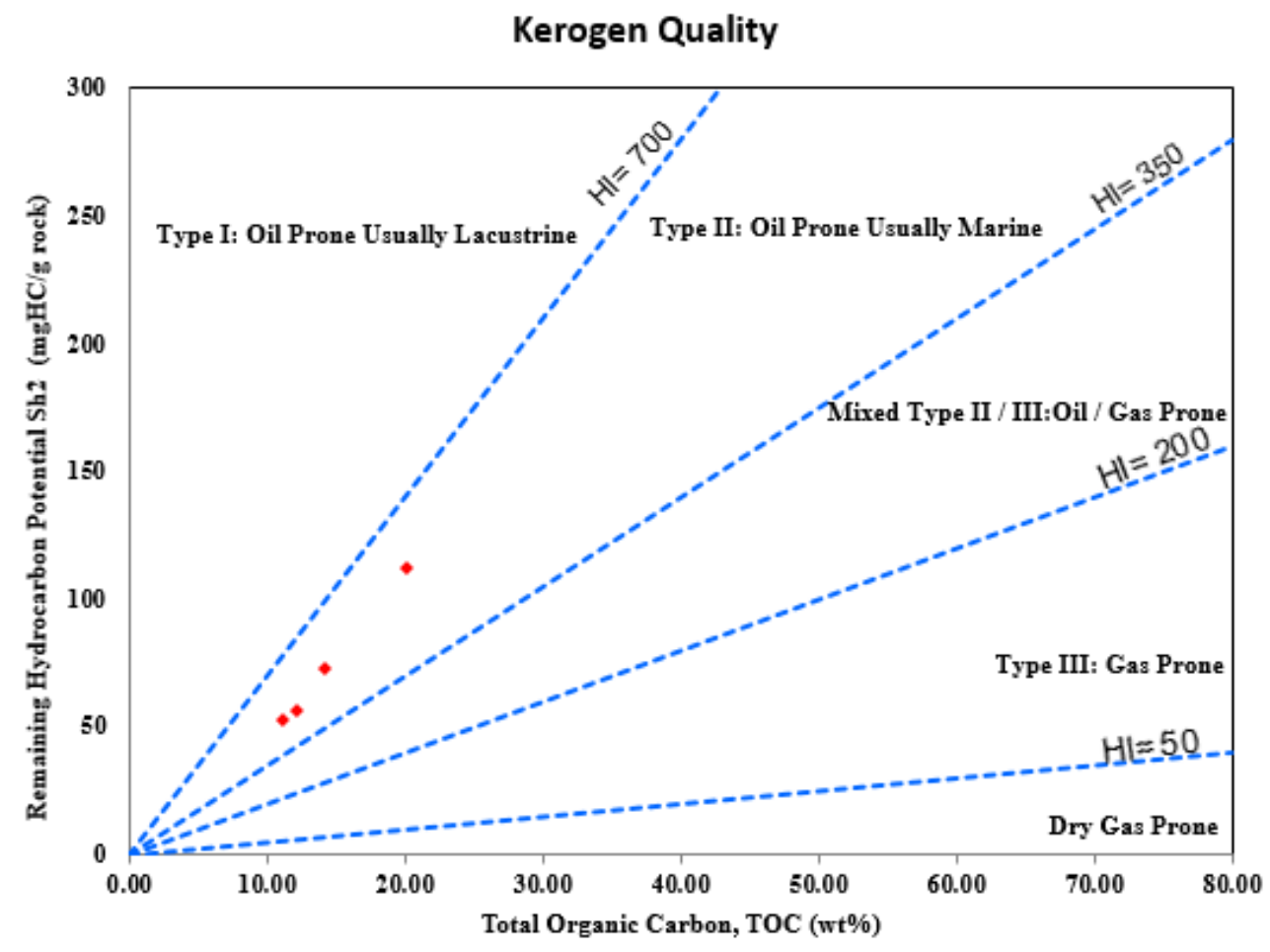

Fig. 5. The plot of Sh2 vs. TOC showing kerogen quality of the four samples.

\subsection{FTIR analysis}

FTIR analysis characterizes the chemical bonds in the samples and helps to understand the existing functional groups and chemical compositions. Fig. 6 displays the FTIR spectrum of bulk shale and the corresponding isolated kerogen samples. Typical peaks that can be seen in both types of samples are detected at about $2850 \mathrm{~cm}^{-1}$ and $2916 \mathrm{~cm}^{-1}$ wavenumber. They represent methylene $\mathrm{CH}_{2}$ and methyl $\mathrm{CH}_{3}$ groups, respectively, from aromatic hydrocarbons. Likewise, the peak at about $1605 \mathrm{~cm}^{-1}$ wavenumber donates the $\mathrm{C}=\mathrm{C}$ bond in the aromatic rings [41-42]. Although some peaks exist in both type of specimens, the intensity of the peak is different. In addition, few peaks in the FTIR spectrum were only detected in the bulk shale samples. This confirms the existence of other compositions, which are missing in the isolated kerogen samples. Considering Sample 2, the peaks around $1094 \mathrm{~cm}^{-1}$ and $749 \mathrm{~cm}^{-1}$ wavenumber, which are obtained from the bulk shale, are larger than the strength of the same peaks in the isolated kerogen. This likely indicates the presence of quartz [43], which agrees with the XRD results.. Two separate indices (A and C) were used to describe the properties of organic matter and to analyze the kerogen type using FTIR data [41]. 
Index $\mathrm{A}$, which is aliphatic $\mathrm{C}-\mathrm{H}_{\mathrm{x}}$ relative to aromatic $\mathrm{C}=\mathrm{C}$ stretching vibrations [32], is defined as the relative intensities of bands maxima of $2916 \mathrm{~cm}^{-1}, 2849 \mathrm{~cm}^{-1}$ and $1605 \mathrm{~cm}^{-1}$ wavenumbers of the FTIR spectrum of the isolated kerogen:

$$
A=\frac{\operatorname{Int}\left(2916 \mathrm{~cm}^{-1}\right)+\operatorname{Int}\left(2849 \mathrm{~cm}^{-1}\right)}{\operatorname{Int}\left(2916 \mathrm{~cm}^{-1}\right)+\operatorname{Int}\left(2849 \mathrm{~cm}^{-1}\right)+\operatorname{Int}\left(1605 \mathrm{~cm}^{-1}\right)}
$$

While index $\mathrm{C}$ is the quotient of band intensities: $1710 \mathrm{~cm}^{-1}(\mathrm{C}=\mathrm{O}$ band $)$ and the sum of the intensities of the $1710 \mathrm{~cm}^{-1}$ and $1605 \mathrm{~cm}^{-1}$ bands of the FTIR spectrum. This idex defines the intensity of the absorbance band related to vibrations of oxygenated functional groups versus aromatic ring functional groups; thus, is an indicator of the relative oxygen content of the sample [32]:

$$
C=\frac{\operatorname{Int}\left(1710 \mathrm{~cm}^{-1}\right)}{\operatorname{Int}\left(1710 \mathrm{~cm}^{-1}\right)+\operatorname{Int}\left(1605 \mathrm{~cm}^{-1}\right)}
$$

The $\mathrm{A}$ and $\mathrm{C}$ values were calculated for all four samples. index $\mathrm{A}$ varies between 0.6-0.7 while index $\mathrm{C}$ is around 0.5, which indicates that the kerogen type in these samples is type II [41]. This is in good agreement with the results from the Rock-Evalpyrolysis.

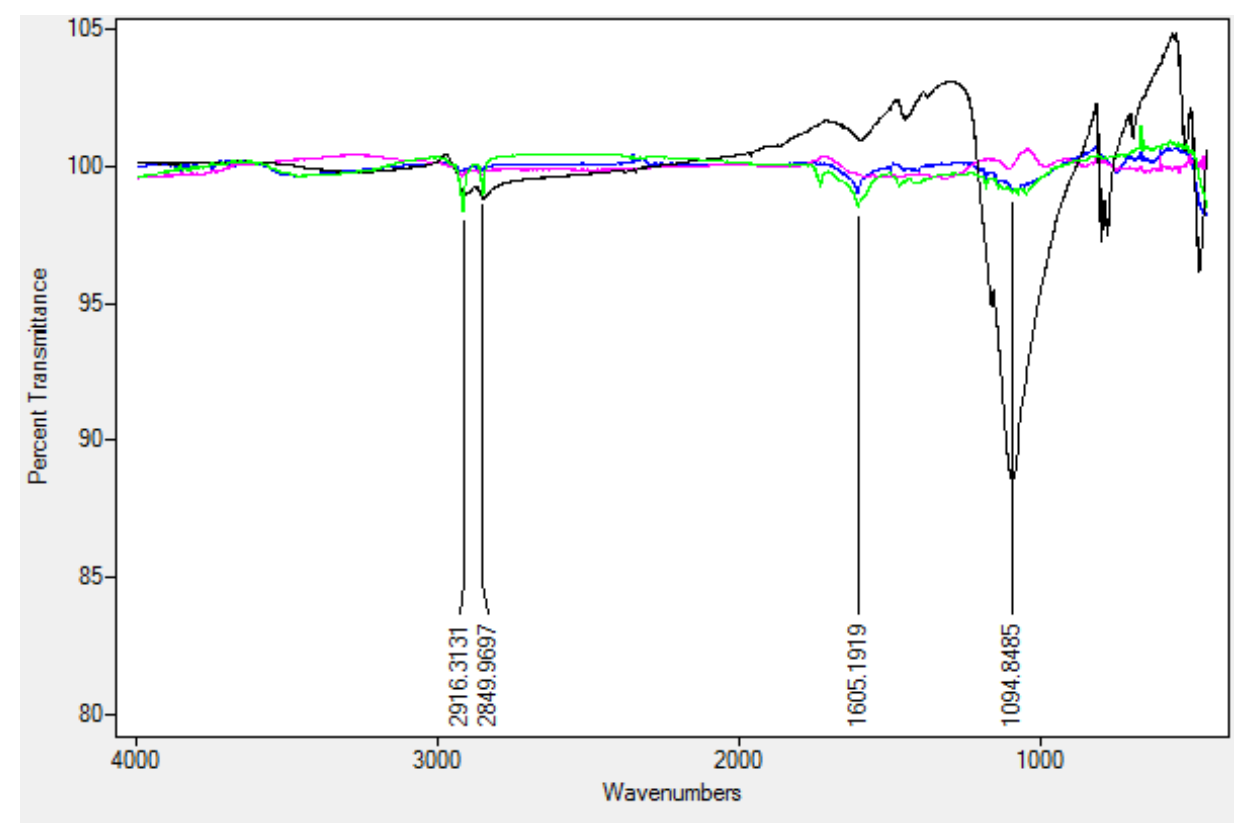

(a) FTIR spectrum of isolated kerogen. 


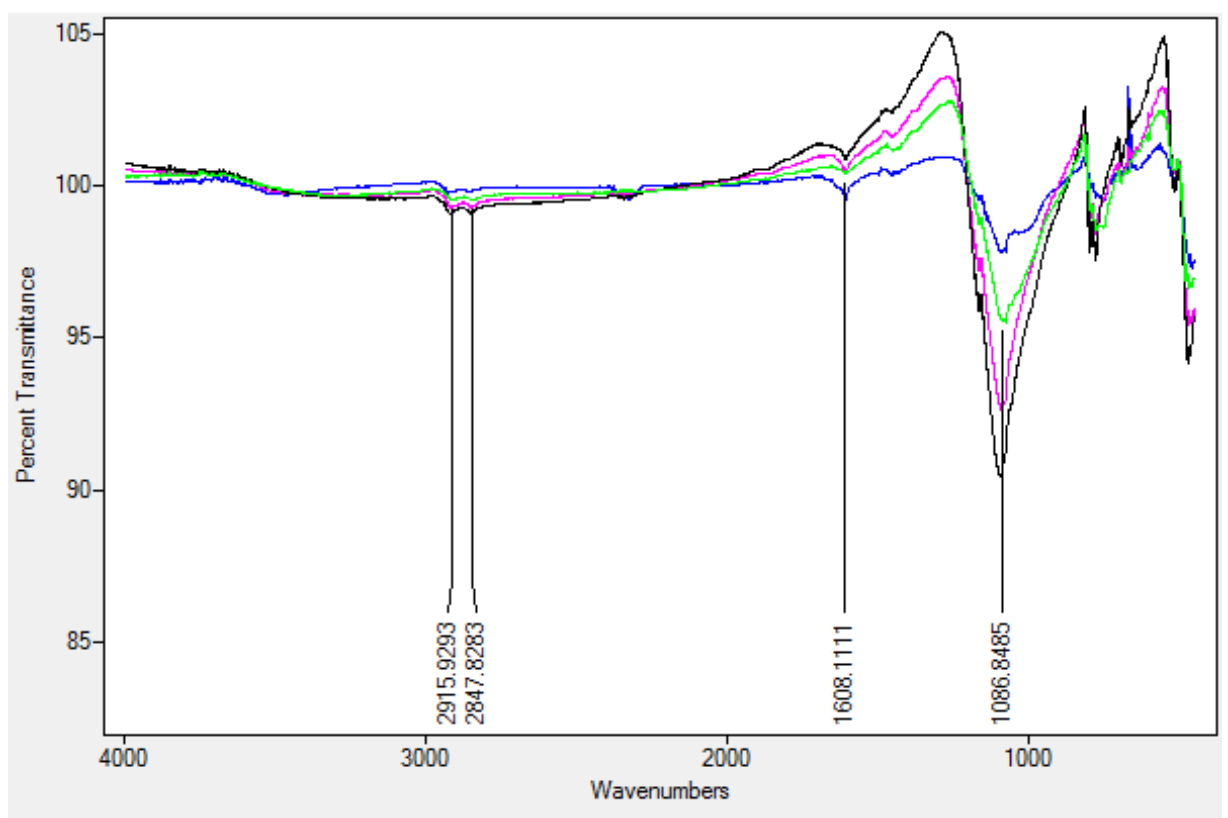

(b) FTIR spectrum of bulk shale samples.

Fig. 6. The FTIR spectrum of isolated kerogen and bulk shale samples (green, blue, pink and black curves represent Sample 1, 2, 3 and 4, respectively).

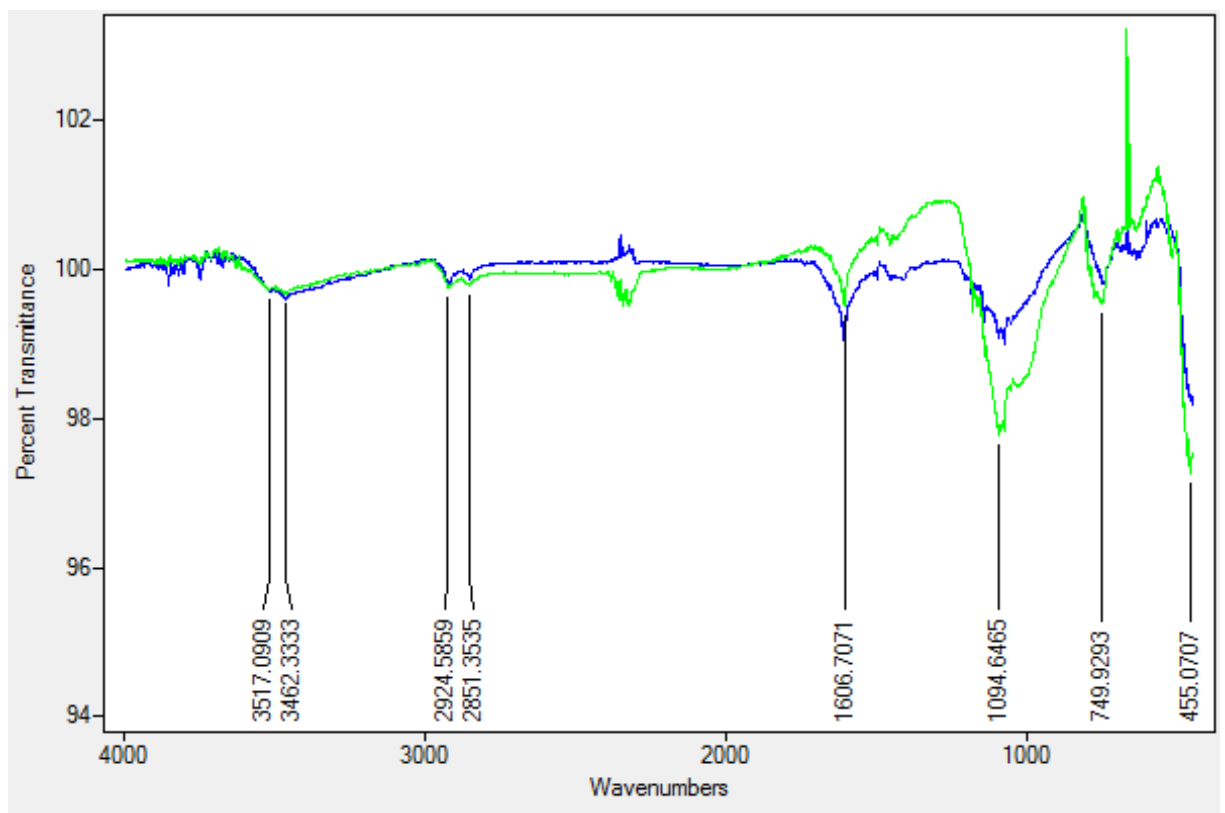

Fig. 7. The FTIR spectrum of Sample 2 (green curve represents the isolated kerogen while the blue donates the bulk shale sample). 


\subsection{Gas Adsorption}

Based on previous studies [18], abundant pores with a size less than $9 \mathrm{~nm}$ exist in the Bakken Shale samples. These pores are beyond the ability of the available SEM in our disposal to detect them due to resolution limitations. In order to quantify these smaller pores, gas adsorption was utilized to analyze and compare the pore structures of the bulk shale samples and their corresponding isolated kerogen.

\subsection{1 $\mathrm{CO}_{2}$ gas adsorption}

Fig. 8 shows $\mathrm{CO}_{2}$ gas adsorption isotherms for the bulk shale samples and the corresponding isolated kerogen. The figures depict an increasing trend of the quantity of the adsorbed gas for both bulk shale and isolated kerogen with an increase in relative pressure. Under the same relative pressure changes, gas adsorption quantity of isolated kerogen was found to be greater than the bulk shale samples. This is a good indication that kerogen hosts more micro pores compared to the bulk shale samples. The summary of the results regarding the volume of micropores for both bulk shale and isolated kerogen can be seen in Table 3. This table explains that the micropore volume of kerogen varies from 0.0059 to $0.0064 \mathrm{~cm}^{3} / \mathrm{g}$ which is 3.5 to 8.5 times greater than the micropore volume of the bulk shale samples. In addition, the micropore surface area of isolated kerogen was found to be from 10.8600 to $11.7931 \mathrm{~m}^{2} / \mathrm{g}$ which is around 3.76-9.92 times more than the micropore surface area of bulk shale samples. As TOC increases, the micropore volume and the micropore surface area both increase (Fig. 9), which indicates the significant influence that kerogen can have on the micropore network of bulk shale samples.

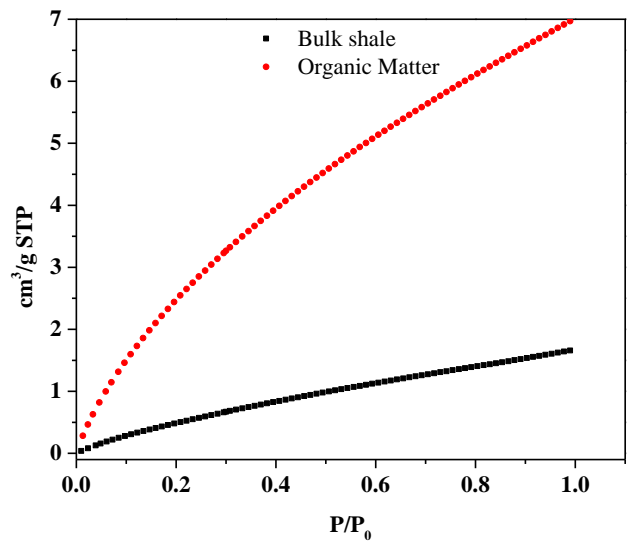

(a) Sample 1

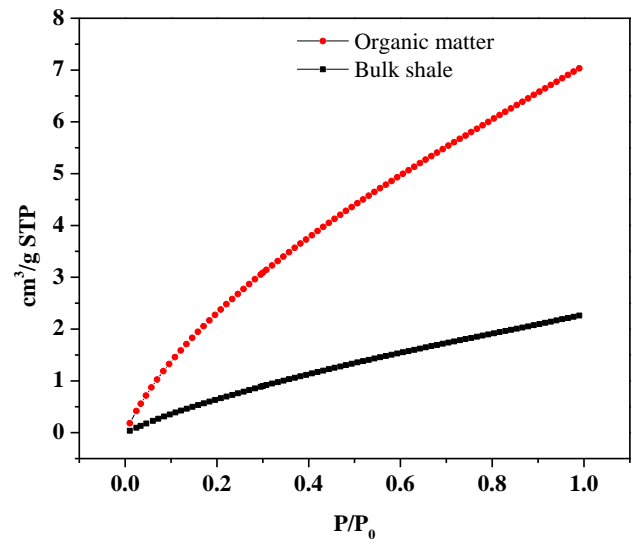

(b) Sample 2 


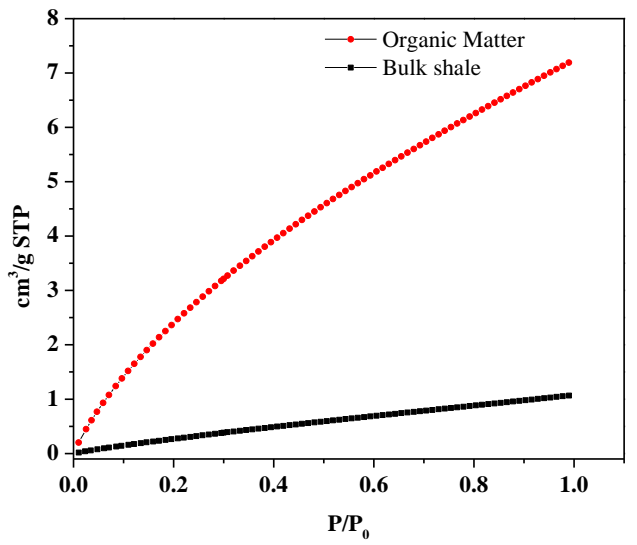

(c) Sample 3

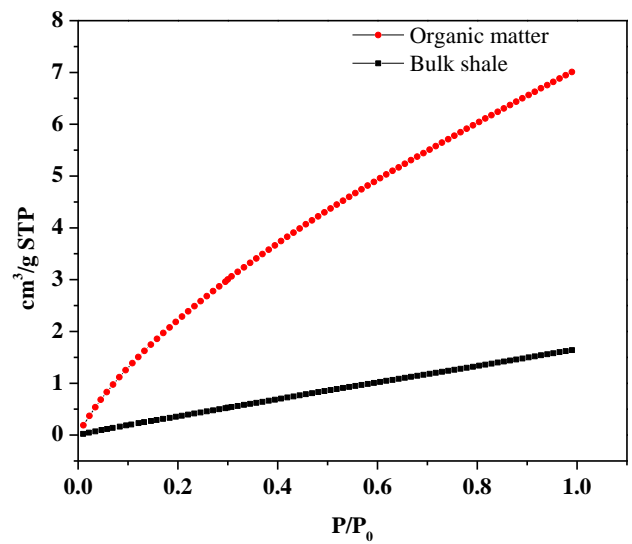

(d) Sample 4

Fig. 8. $\mathrm{CO}_{2}$ gas adsorption isotherms of bulk shale and isolated kerogen samples.

Table 3 Summary and comparison of micropore characteristics of our samples from $\mathrm{CO}_{2}$ gas adsorption (bulk shale and isolated kerogen samples).

\begin{tabular}{lcccc}
\hline & \multicolumn{2}{c}{ Bulk shale } & \multicolumn{2}{c}{ Isolated kerogen } \\
\cline { 2 - 5 } & $\begin{array}{c}\text { micro pore volume, } \\
\mathbf{c m}^{3} / \mathbf{g}\end{array}$ & $\begin{array}{c}\text { micro pore surface, } \\
\mathbf{m}^{2} / \mathbf{g}\end{array}$ & $\begin{array}{c}\text { micro pore volume, } \\
\mathbf{\mathbf { c m } ^ { 3 } / \mathbf { g }}\end{array}$ & $\begin{array}{c}\text { micro pore surface, } \\
\mathbf{\mathbf { m } ^ { 2 } / \mathbf { g }}\end{array}$ \\
\hline Sample 1 & 0.0013 & 2.3757 & 0.0064 & 10.9632 \\
\hline Sample 2 & 0.0018 & 3.0040 & 0.0061 & 11.3061 \\
\hline Sample 3 & 0.0008 & 1.1882 & 0.0064 & 11.7931 \\
\hline Sample 4 & 0.0010 & 1.5708 & 0.0059 & 10.8600 \\
\hline
\end{tabular}

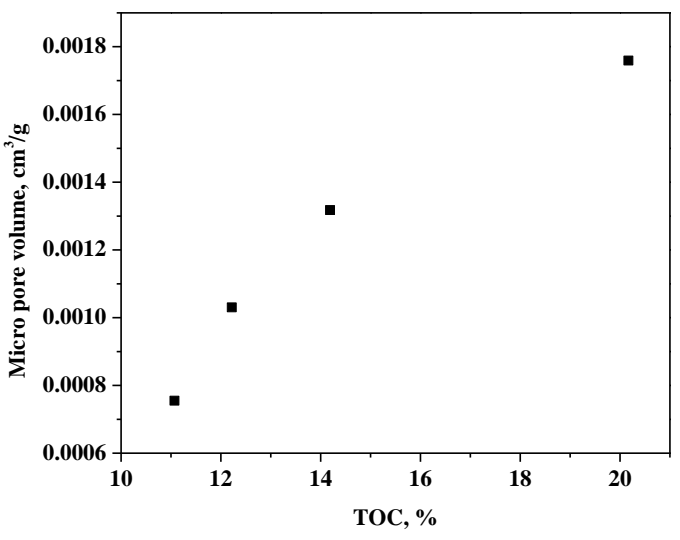

(a) Micropore volume

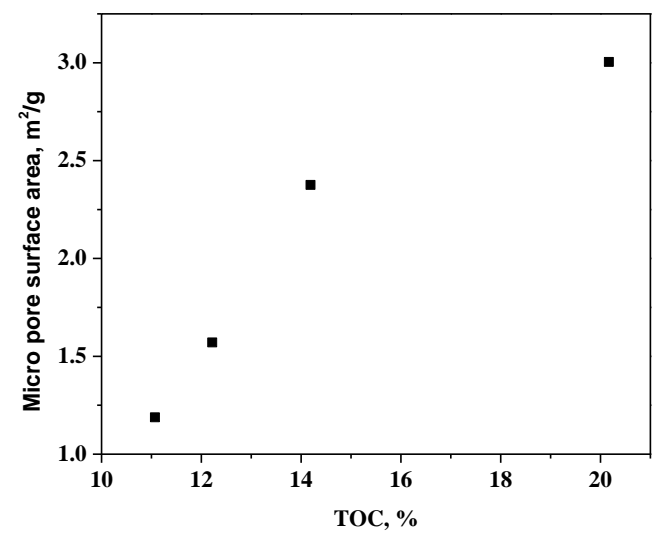

(b) Micropore surface area 
Fig. 9. The impact of TOC on pore structures of bulk shale samples.

\subsection{2. $\mathrm{N}_{2}$ gas adsorption}

The $\mathrm{N}_{2}$ adsorption isotherms for the isolated kerogen and bulk shale samples are shown in Fig. 10 (a-d). In order to gain a better understanding of $\mathrm{N}_{2}$ adsorption behavior on bulk shale samples in particular, Sample 1 and Sample 2 are replotted on a magnified y-axis (volume of adsorbed gas), which is displayed in Fig. 10 (e and f), respectively. The $\mathrm{N}_{2}$ adsorption isotherms of both bulk shale and isolated kerogen show a hysteresis behavior, which shows the existence of mesopores in both sample types. However, a closer look at the shape of the hysteresis loop demonstrates that the main pore type in the isolated kerogen are silt-shaped pores while the main pore type in the bulk shale samples is a combination of silt-shaped pores and ink-bottle pores [22,44]. Table 4 is a summary of the comparison of the meso-macropore of the bulk shale and the isolated kerogen samples. When gas adsorption is the method for quantifying PSD in a sample, the BrunauerEmmett-Teller (BET) theory can be applied to the multilayer adsorption data because the probing gas does not chemically react with material surface. Thus, the BET theory enables to quantify the specific surface area of the absorbates. The BET surface area of the isolated kerogen in the studied samples varies from $14.1837-18.2964 \mathrm{~m}^{2} / \mathrm{g}$, which is almost 2.97 to 5.83 times greater than the BET surface area of the bulk shale samples. Mesopore volume of the isolated kerogen varies from $0.0347-0.0414 \mathrm{~cm}^{3} / \mathrm{g}$, which is about 3.03-4.49 times of the mesopore volume of the bulk shale samples. While comparing macropore volume of these two separate specimens, it turns out that isolated kerogen macropore volume is 2.98-9.21 times as large as the bulk shale macropore volume. The overall analysis of pore volumes concludes that meso-macropores are more abundant in the isolated kerogen compared to the bulk shale samples.
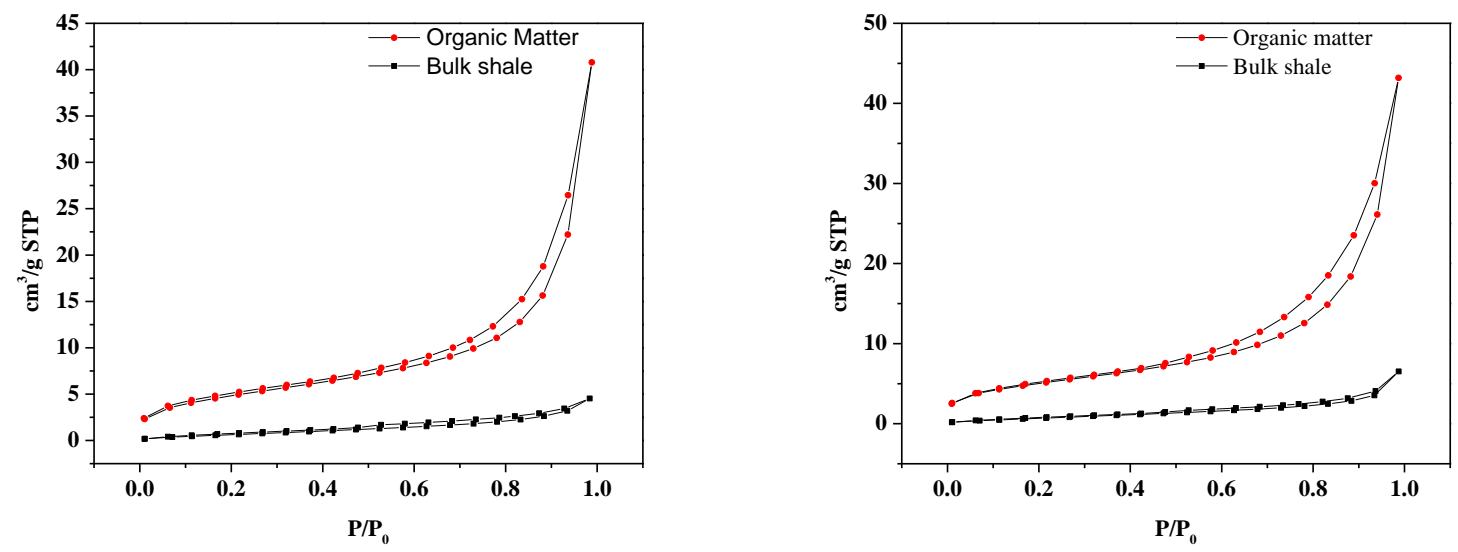
(a)

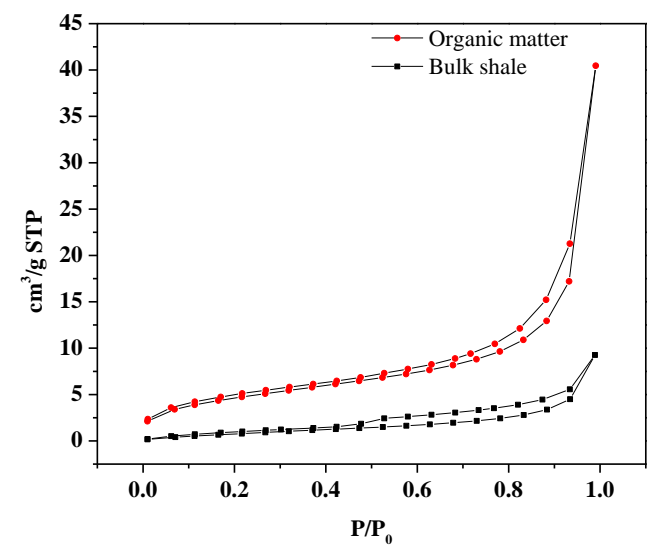

(c)

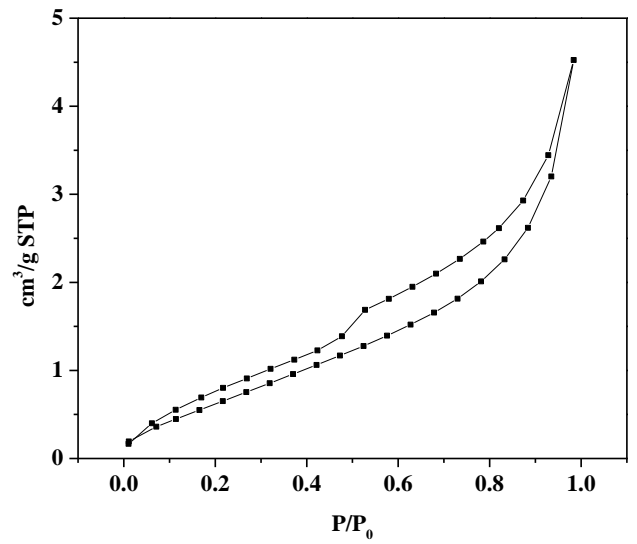

(e)

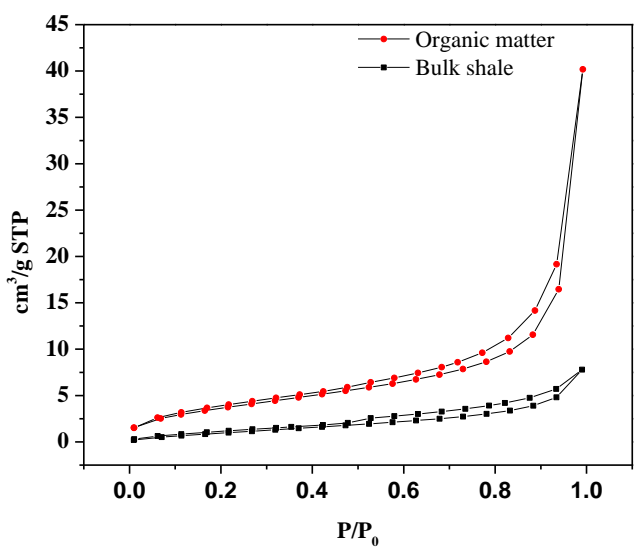

(d)

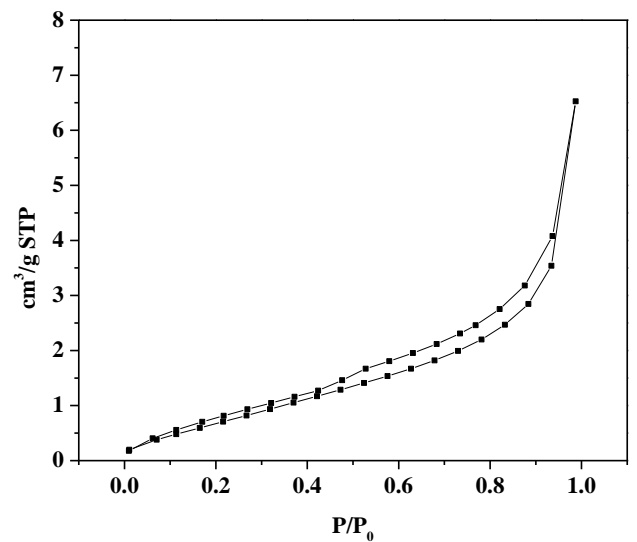

(f)

Fig. 10. (a-d) $\mathrm{N}_{2}$ adsorption isotherms of bulk shale and isolated kerogen of Samples 1-4 respectively. (e and f) the magnified and replotted isotherms of bulk shale Sample 1 and 2.

Table 4 Summary of the meso-macropore surface and volume data of all studied samples obtained from $\mathrm{N}_{2}$ gas adsorption. 


\begin{tabular}{lcccccc}
\hline & \multicolumn{3}{c}{ Bulk shale } & \multicolumn{3}{c}{ Isolated kerogen } \\
\hline $\begin{array}{c}\text { BET } \\
\text { surface, } \\
\mathbf{~}^{2} / \mathbf{g}\end{array}$ & $\begin{array}{c}\text { meso-pore } \\
\text { volume, } \\
\mathbf{c m}^{3} / \mathbf{g}\end{array}$ & $\begin{array}{c}\text { macro-pore } \\
\text { volume, } \\
\mathbf{c m}^{3} / \mathbf{g}\end{array}$ & $\begin{array}{c}\text { BET } \\
\text { surface, } \\
\mathbf{m}^{2} / \mathbf{g}\end{array}$ & $\begin{array}{c}\text { meso-pore } \\
\text { volume, } \\
\mathbf{c m}^{3} / \mathbf{g}\end{array}$ & $\begin{array}{c}\text { macro-pore } \\
\text { volume, } \\
\mathbf{c m}^{3} / \mathbf{g}\end{array}$ \\
\hline Sample 1 & 3.0443 & 0.0063 & 0.0005 & 17.7603 & 0.0347 & 0.0042 \\
\hline Sample 2 & 3.3616 & 0.0085 & 0.0013 & 18.2964 & 0.0414 & 0.0052 \\
\hline Sample 3 & 3.8389 & 0.0118 & 0.0023 & 16.9721 & 0.0356 & 0.0069 \\
\hline Sample 4 & 4.7688 & 0.0102 & 0.0015 & 14.1837 & 0.0413 & 0.0120 \\
\hline
\end{tabular}

\subsection{Pore size distributions (PSD)}

The pore size distribution (PSD) curves of four bulk shale samples and their corresponding extracted isolated kerogen were analyzed separately and compared. Fig. 11 displays the micropore size distributions of the bulk shale and their corresponding isolated kerogen samples. The comparison of micropore size distribution curves of these two different sets of specimens confirms that major peaks less than $1 \mathrm{~nm}$ on the $\mathrm{x}$-axis (pore size) do not overlap with one another, while they coincide when micropore sizes are larger than $1 \mathrm{~nm}$. This signifies that isolated kerogen contributes mostly to micropores with sizes larger than $1 \mathrm{~nm}$.

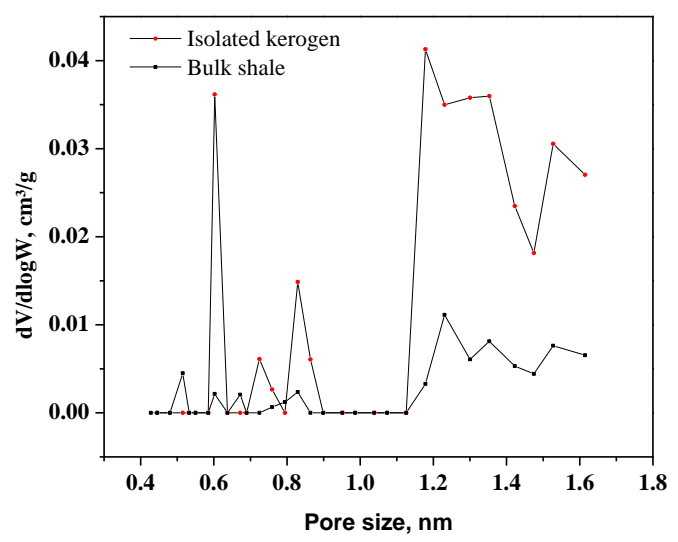

(a) Sample 1

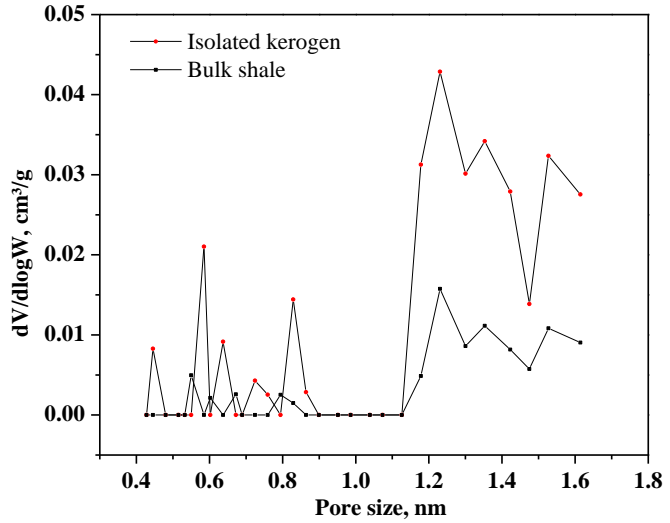

(2) Sample 2 


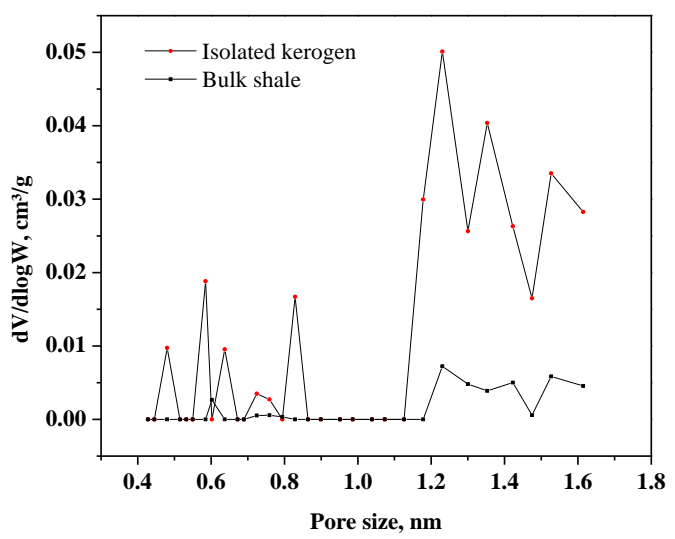

(c) Sample 3

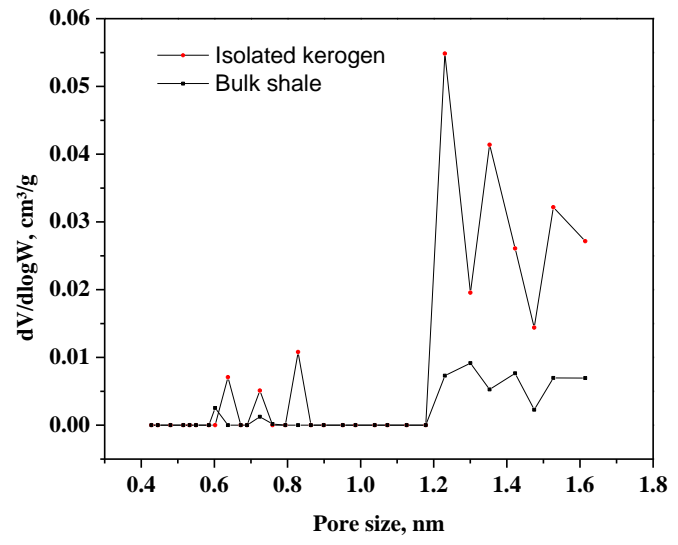

(d) Sample 4

Fig. 11. Pore size distribution (PSD) curves of bulk shale and isolated kerogen samples.

The meso- and macropore size distributions of bulk shale and isolated kerogen samples from $\mathrm{N}_{2}$ gas adsorption method were also analyzed and compared. Pore size distributions (PSD) of all samples exhibit a multimodal characteristic, which can be interpreted to indicate the presence of various pore groups/clusters. Therefore, in order to quantify different existing pore groups from pore size distribution perspective, a deconvolution method was applied to the data. To perform this method, each pore cluster/family should fit the normal/Gaussian distribution with specific mean pore size $(\mathrm{u})$ and standard deviation $\left(\mathrm{s}_{\mathrm{d}}\right)[18,45,46]$. In Fig 12, the blue curve represents the experimental data while the red dashed line represents the fitted curves after deconvolving the data. From the fitted curves after data deconvolution is completed, it can be concluded that meso- and macropore size distributions in isolated kerogen samples can be separated into five distinguished pore cluster/families while the meso- and macropore size distribution of the bulk shale samples can be divided into six different pore families/clusters. The deconvolution details of pore size distribution for the bulk shale and isolated kerogen samples are summarized in Table 5 and Table 6 , respectively. Comparison of the data presented in these two tables illustrates that both types of specimens have similar pore clusters. To be more specific, pore clusters retrieved from the bulk shale samples and which are labeled as families 2, 3, 4, 5 and 6 also exist in the isolated kerogen samples. Pore families in the isolated kerogen samples were labelled as 1, 2, 3, 4 and 5, and have the same characteristics as the bulk shale pore families. However, there exists an additional pore cluster with an average diameter of $4 \mathrm{~nm}$ in the bulk shale samples, which could be referred to as 
pores that are related to minerals. This latest finding agrees with the results of other researchers [10].

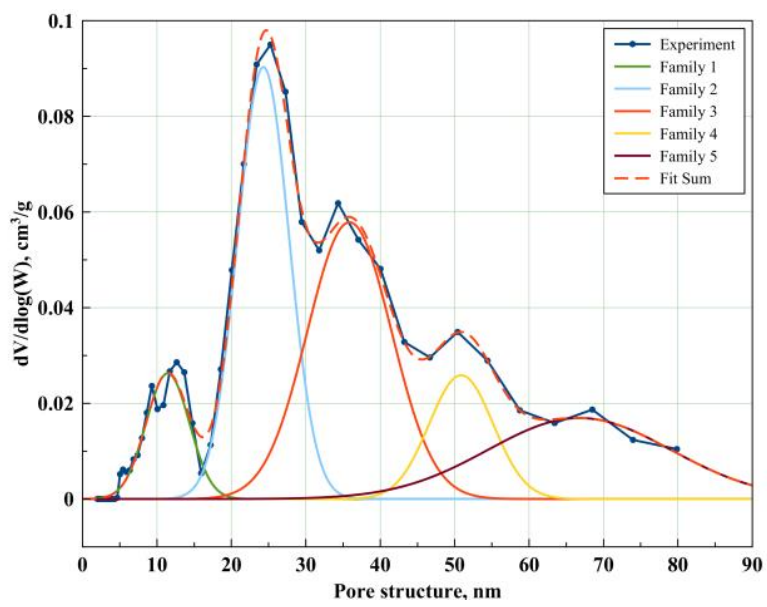

(a)

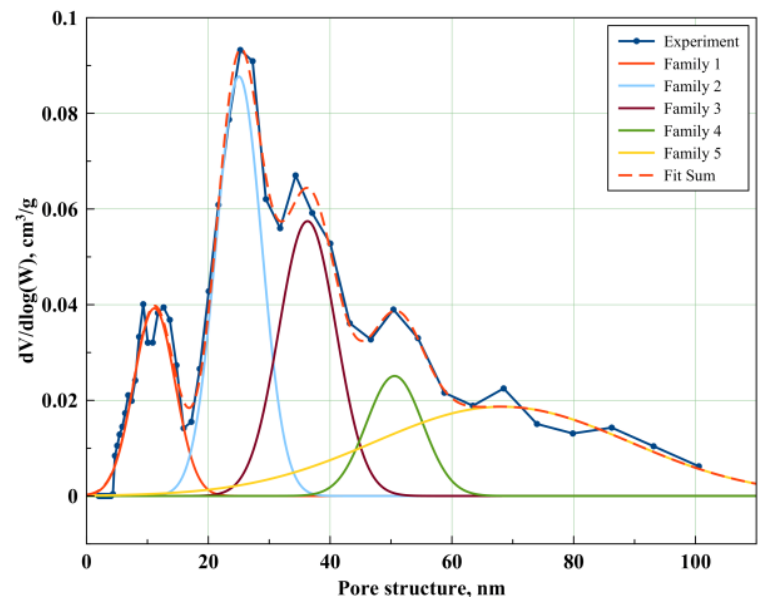

(c)

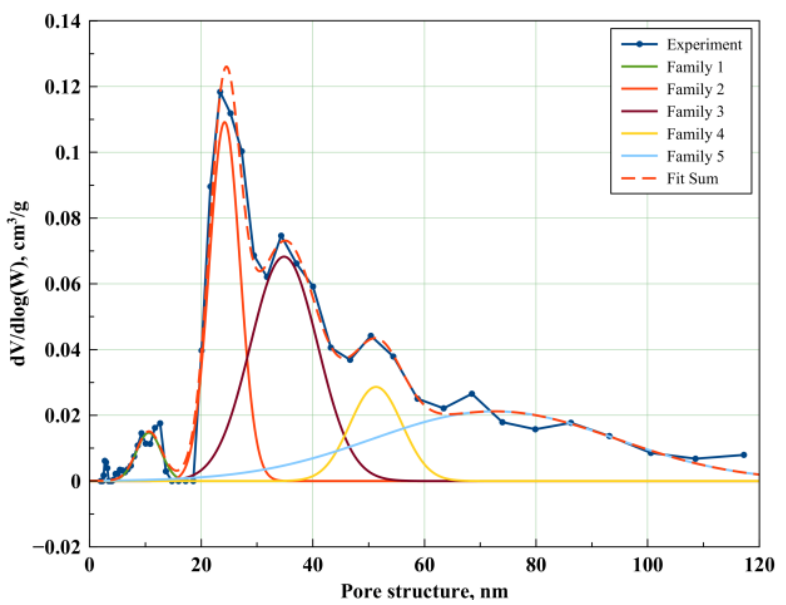

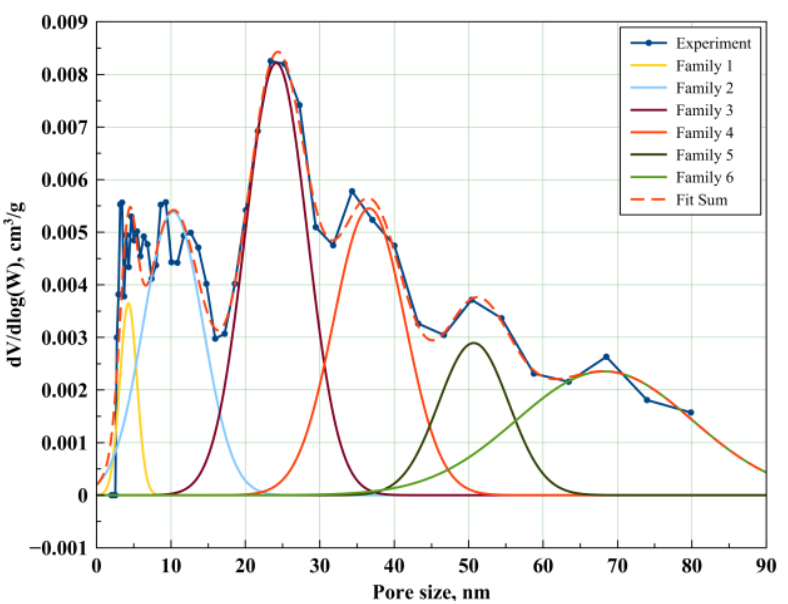

(b)

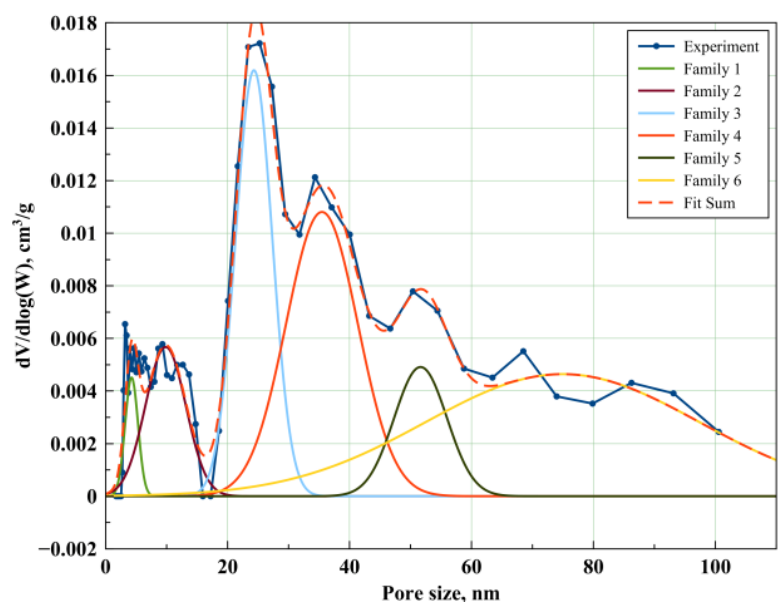

(d)

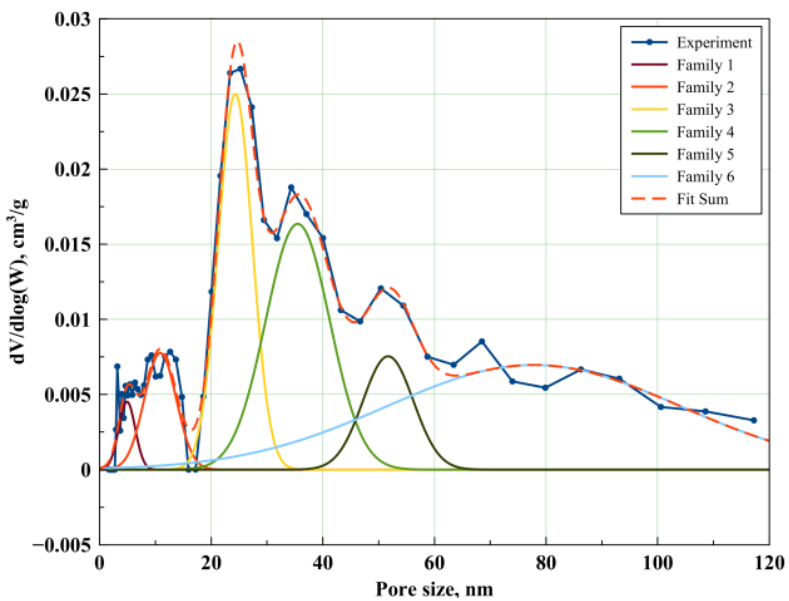


(e)

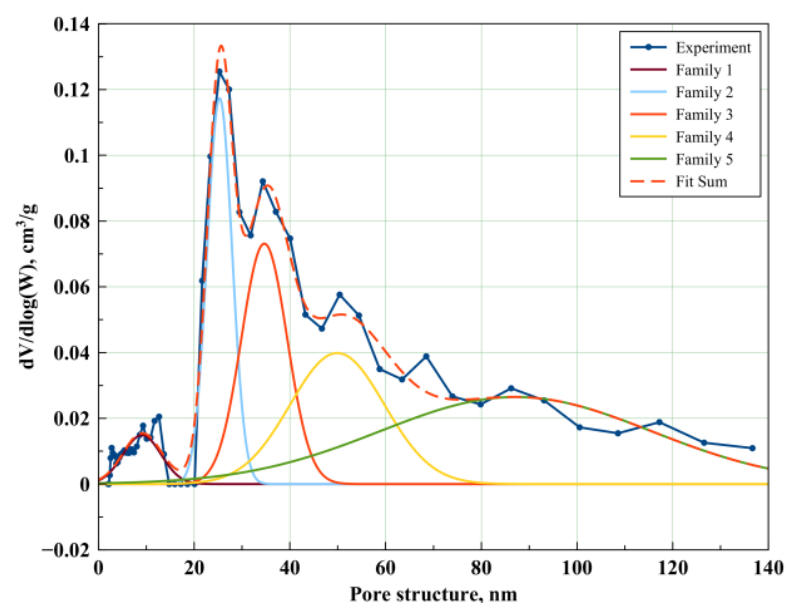

(e) (f)

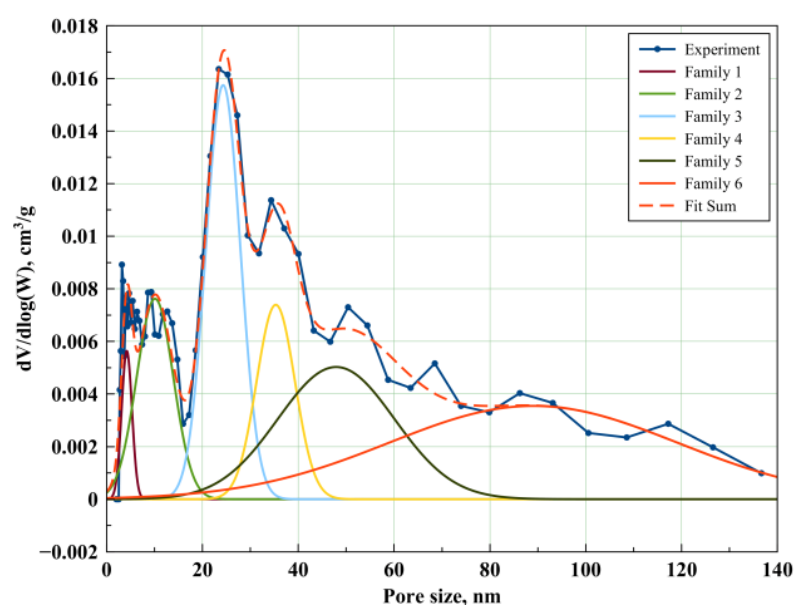

(f)

Fig. 12. The meso- and macropore size distribution curves of bulk shale (b, $d, f$, and $h$ ) and isolated kerogen samples (a, c, e and g). The blue solid curve refers to experimental data and the red dashed line refers to the sum of the fitted curve after data deconvolution.

Table 5 The details of deconvolution results of pore size distributions of bulk shale samples showing 6 different pore clusters.

\begin{tabular}{ccccccccccccc}
\hline & \multicolumn{2}{c}{ Family 1 } & \multicolumn{2}{c}{ Family 2 } & \multicolumn{2}{c}{ Family 3 } & \multicolumn{2}{c}{ Family 4 } & \multicolumn{2}{c}{ Family 5 } & \multicolumn{2}{c}{ Family 6 } \\
\cline { 2 - 14 } & $\begin{array}{c}\mathbf{u}, \\
\mathbf{n m}\end{array}$ & $\begin{array}{c}\mathbf{S}_{\mathbf{d}}, \\
\mathbf{n m}\end{array}$ & $\begin{array}{c}\mathbf{u}, \\
\mathbf{n m}\end{array}$ & $\begin{array}{c}\mathbf{S}_{\mathbf{d}}, \\
\mathbf{n m}\end{array}$ & $\begin{array}{c}\mathbf{u}, \\
\mathbf{n m}\end{array}$ & $\begin{array}{c}\mathbf{s}_{\mathbf{d}}, \\
\mathbf{n m}\end{array}$ & $\begin{array}{c}\mathbf{u}, \\
\mathbf{n m}\end{array}$ & $\begin{array}{c}\mathbf{s}_{\mathbf{d}}, \\
\mathbf{n m}\end{array}$ & $\begin{array}{c}\mathbf{u}, \\
\mathbf{n m}\end{array}$ & $\begin{array}{c}\mathbf{S}_{\mathbf{d}}, \\
\mathbf{n m}\end{array}$ & $\begin{array}{c}\mathbf{u}, \\
\mathbf{n m}\end{array}$ & $\begin{array}{c}\mathbf{S}_{\mathbf{d}}, \\
\mathbf{n m}\end{array}$ \\
\hline Sample 1 & 4.28 & 0.18 & 10.28 & 0.57 & 24.15 & 0.97 & 36.64 & 1.48 & 50.68 & 3.01 & 68.23 & 10.89 \\
\hline Sample 2 & 4.25 & 0.19 & 9.83 & 0.53 & 24.32 & 0.36 & 35.47 & 1.00 & 51.65 & 1.71 & 74.94 & 8.21 \\
\hline Sample 3 & 4.92 & 0.45 & 10.88 & 0.49 & 24.32 & 0.31 & 35.50 & 0.80 & 51.70 & 1.49 & 77.78 & 7.15 \\
\hline Sample 4 & 4.22 & 0.17 & 10.09 & 0.55 & 24.31 & 0.48 & 35.30 & 1.14 & 47.91 & 10.36 & 89.06 & 27.12 \\
\hline
\end{tabular}

Note: $\mathrm{u}$ refers to the mean value while $\mathrm{s}_{\mathrm{d}}$ is the standard deviation.

Table 6 The details of deconvolution results of pore size distributions of isolated kerogen showing five different clusters.

\begin{tabular}{ccccccccccc}
\hline & \multicolumn{2}{c}{ Family 1 } & \multicolumn{2}{c}{ Family $\mathbf{2}$} & \multicolumn{2}{c}{ Family 3} & \multicolumn{2}{c}{ Family $\mathbf{4}$} & \multicolumn{2}{c}{ Family $\mathbf{5}$} \\
\cline { 2 - 11 } & $\begin{array}{c}\mathbf{u}, \\
\mathbf{n m}\end{array}$ & $\begin{array}{c}\mathbf{S}_{\mathbf{d}}, \\
\mathbf{n m}\end{array}$ & $\begin{array}{c}\mathbf{u}, \\
\mathbf{n m}\end{array}$ & $\begin{array}{c}\mathbf{S}_{\mathbf{d}}, \\
\mathbf{n m}\end{array}$ & $\begin{array}{c}\mathbf{u}, \\
\mathbf{n m}\end{array}$ & $\begin{array}{c}\mathbf{S}_{\mathbf{d}}, \\
\mathbf{n m}\end{array}$ & $\begin{array}{c}\mathbf{u}, \\
\mathbf{n m}\end{array}$ & $\begin{array}{c}\mathbf{s}_{\mathbf{d}}, \\
\mathbf{n m}\end{array}$ & $\begin{array}{c}\mathbf{u}, \\
\mathbf{n m}\end{array}$ & $\begin{array}{c}\mathbf{S}_{\mathbf{d}}, \\
\mathbf{n m}\end{array}$ \\
\hline Sample 1 & 11.45 & 0.22 & 24.30 & 0.25 & 35.86 & 0.55 & 50.87 & 1.02 & 66.77 & 6.00 \\
\hline Sample 2 & 11.14 & 0.22 & 25.03 & 0.38 & 36.29 & 0.59 & 50.59 & 1.29 & 68.25 & 10.47 \\
\hline
\end{tabular}




\begin{tabular}{ccccccccccc} 
Sample 3 & 10.62 & 0.50 & 24.20 & 0.19 & 34.85 & 0.69 & 51.33 & 1.46 & 72.56 & 7.74 \\
\hline Sample 4 & 9.08 & 0.80 & 25.31 & 0.24 & 34.64 & 0.71 & 49.89 & 4.14 & 87.20 & 11.11 \\
\hline
\end{tabular}

Note: $\mathrm{u}$ refers to the mean value while $\mathrm{s}_{\mathrm{d}}$ is the standard deviation.

\subsection{Pore heterogeneity}

Multifractal theory was applied to the gas adsorption data in order to study the heterogeneity that may exist in the pore size distributions of the bulk shale and corresponding isolated kerogen samples. $\mathrm{CO}_{2}$ and $\mathrm{N}_{2}$ adsorption data were analyzed separately to enable to independently demonstrate the micropore heterogeneity and meso- and macropore heterogeneity, respectively. $\alpha_{\mathrm{q}}$, which was earlier defined as the singularity spectrum, was calculated and is shown in Fig. 13 and Fig. 14, which decreases as $q$ increases. This relationship confirms a fractal characteristic in our data. Based on this, multifractal analysis can be applied to analyze the micropore and mesoand macropore heterogeneities of both bulk shale and isolated kerogen samples.

Fig. 13 and Fig. 14 help calculate the fluctuations of the maximum probability $\left(\alpha_{\max }\right)$ and minimum probability $\left(\alpha_{\min }\right)$ of pore size distributions. The extension of the singularity length $(\Delta \alpha)$ which is the difference between the $\alpha_{\max }$ and $\alpha_{\min }$ can characterize the degree of heterogeneity of pore size distributions in our samples [47]. The results that is summarized in Table 7 explains that micropore heterogeneity of bulk shale samples is much less than the micropore heterogeneity of isolated kerogen (using the $\mathrm{CO}_{2}$ adsorption data). Based on the above analysis, one can conclude that micropores exist in the minerals of the Bakken Shale samples. As a matter of fact, the presence of these specific types of pores can reduce the magnitude of micropore heterogeneity of the bulk shale samples. Considering the heterogeneity of meso-macropores (from nitrogen adsorption data), the bulk shale samples were found to have a smaller heterogeneity than isolated kerogen, except for Sample 2. The meso-macropores that exist in the Bakken Shale minerals could reduce or enhance the level of heterogeneity within the samples and should be examined separately in each sample. 


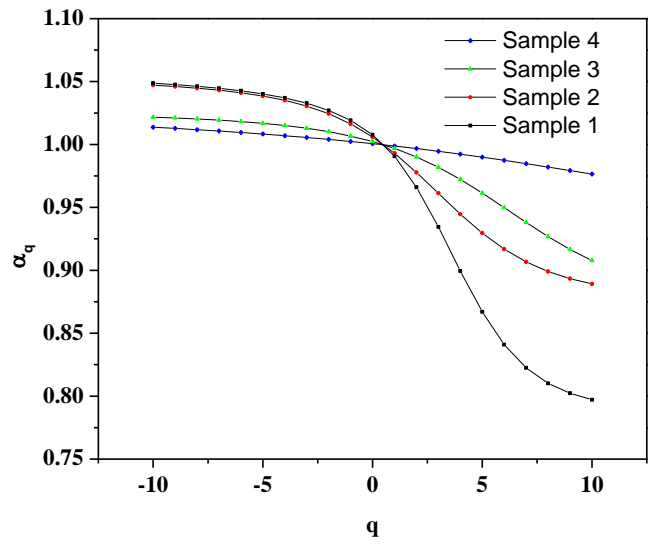

(a) Micropore

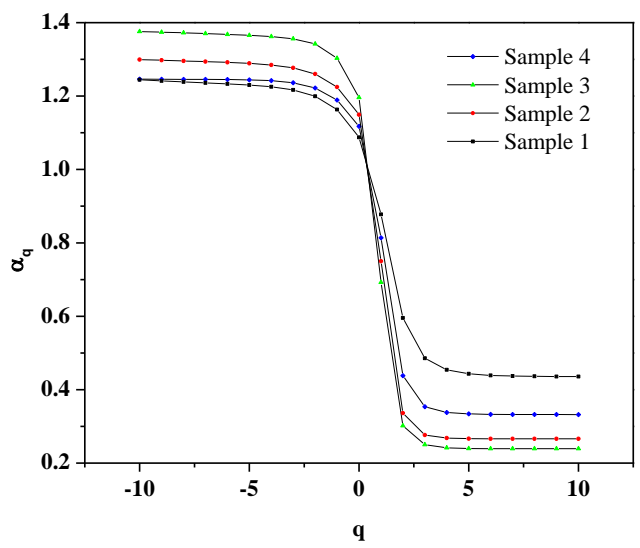

(b) Meso-macropore

Fig. 13. The multifractal spectrum of bulk shale samples. (a) micropores by $\mathrm{CO}_{2}$ gas adsorption, (b) meso-and macropores obtained by $\mathrm{N}_{2}$ gas adsorption.

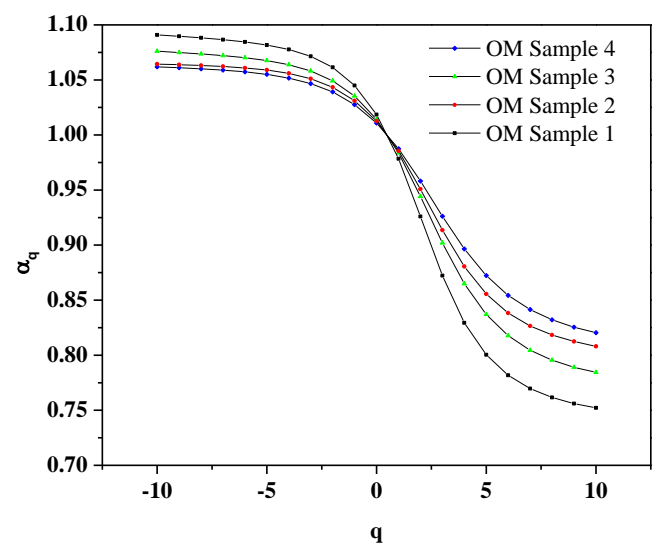

(a) Micropores

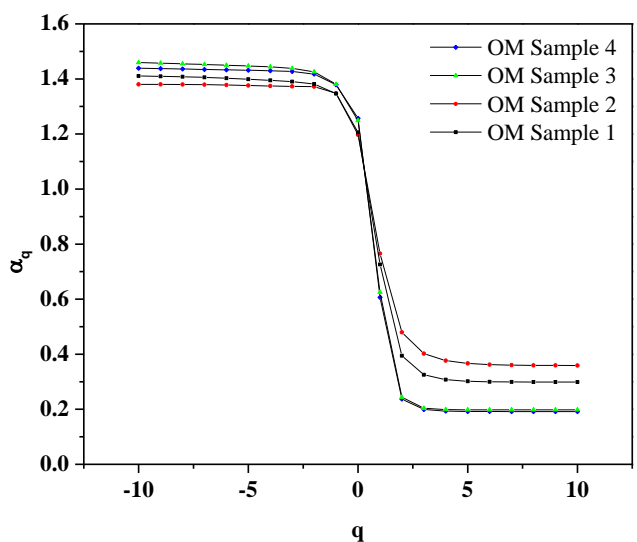

(b) Meso- and macropores

Fig. 14. The multifractal spectrum of isolated kerogen samples. (a) micropores by $\mathrm{CO}_{2}$ gas adsorption and (b) meso- and macropores obtained by $\mathrm{N}_{2}$ gas adsorption.

Table 7 The details of multifractal analysis results from bulk shale and isolated kerogen samples.

\begin{tabular}{ccccccc}
\hline & \multicolumn{4}{c}{ Micropores } & \multicolumn{3}{c}{ Meso- and macropores } \\
\hline$\alpha_{\max }$ & $\alpha_{\min }$ & $\Delta \alpha$ & $\alpha_{\max }$ & $\alpha_{\min }$ & $\Delta \alpha$ \\
\hline
\end{tabular}




\begin{tabular}{cccccccc}
\multirow{2}{*}{ Sample 1} & Bulk shale & 1.049 & 0.797 & 0.252 & 1.244 & 0.436 & 0.809 \\
\cline { 2 - 8 } & Isolated kerogen & 1.091 & 0.752 & 0.339 & 1.411 & 0.299 & 1.112 \\
\hline \multirow{2}{*}{ Sample 2 } & Bulk shale & 1.047 & 0.889 & 0.158 & 1.300 & 0.266 & 1.033 \\
\cline { 2 - 8 } & Isolated kerogen & 1.064 & 0.808 & 0.256 & 1.380 & 0.359 & 1.021 \\
\hline \multirow{2}{*}{ Sample 3 } & Bulk shale & 1.022 & 0.908 & 0.114 & 1.376 & 0.239 & 1.137 \\
\cline { 2 - 8 } & Isolated kerogen & 1.076 & 0.784 & 0.292 & 1.460 & 0.198 & 1.262 \\
\hline \multirow{2}{*}{ Sample 4 } & Bulk shale & 1.014 & 0.977 & 0.037 & 1.246 & 0.332 & 0.914 \\
\cline { 2 - 8 } & Isolated kerogen & 1.062 & 0.820 & 0.242 & 1.439 & 0.192 & 1.247 \\
\hline
\end{tabular}

Comparing the pore structures within the isolated kerogen, it is implicit that micropore volume $\left(0.006 \mathrm{~cm}^{3} / \mathrm{g}\right)$ and micropore surface area $\left(11 \mathrm{~m}^{2} / \mathrm{g}\right)$ do not change and are very similar among the four studied samples. However, meso- and macropore surface area and pore volume analysis of isolated kerogen samples reflects discrepancies among the samples. Kerogen that was isolated from Sample 4 with the largest meso- and macropore volume has the smallest surface area. This can be inferred to indicate that this specific sample has the largest average pore size diameter. Considering thermal maturity, Sample 1 and 2 have similar maturity (VRo-eq=0.56\%) and contain the same kerogen type (type II). However, pore structures of Sample 1 and Sample 2 are not identical. The isolated kerogen from Sample 2 has a larger surface area and also larger meso- and macropore volume than Sample 1. Furthermore, the heterogeneity of pore size distribution of micropores and meso- and macropores of these two samples was also found to be dissimilar. In particular, the isolated kerogen from Sample 1 has larger micro and meso- and macropore heterogeneity than the isolated kerogen from Sample 2. Sample 3 and Sample 4 with similar geochemical characteristics have also reflected some differences in pore structures. One potential reason for such a discrepancy could be related to the kerogen itself. The kerogen in each sample may have been formed from various living organisms, which results in having different molecular compositions, although they have similar kerogen type and thermal maturity. This can also be verified by the results from the FTIR spectrum of the isolated kerogen in Fig. 6a, which shows the presence of different chemical compounds in each isolated kerogen sample.

\subsection{The impact organic matter on the pore structure}

In order to investigate the role that kerogen plays on the bulk shale pore structures, the pore size distributions (PSD) curves of the bulk shale samples (1gr) and the weight normalized organic content in the bulk shale (defined as $1 \mathrm{gr} \times$ TOC) were compared. Fig. 15 illustrates the comparison 
results of micropore size distributions of the bulk shale and the extracted and weight-normalized kerogen samples. It can be concluded that both minerals and kerogen host micropores; however, kerogen hosts more than $60 \%$ of the total micropores that exists in the bulk shale samples.

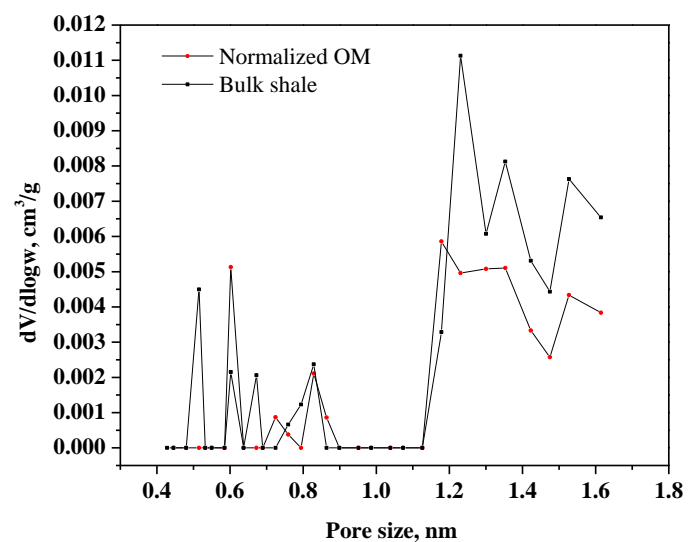

(a) Sample 1

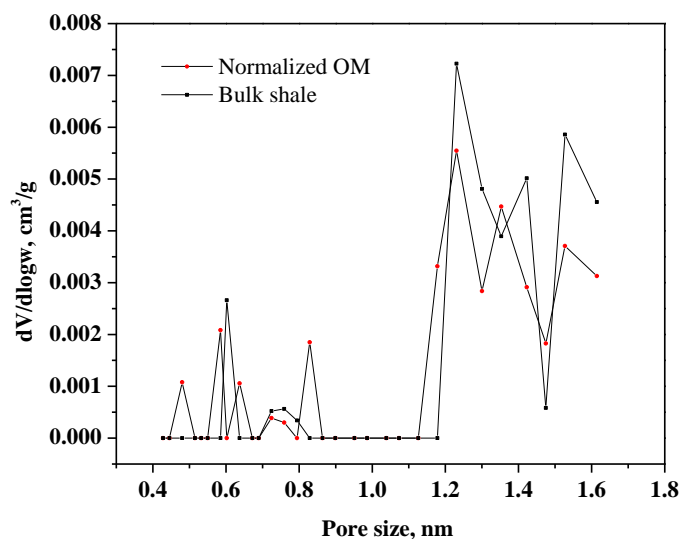

(c) Sample 3

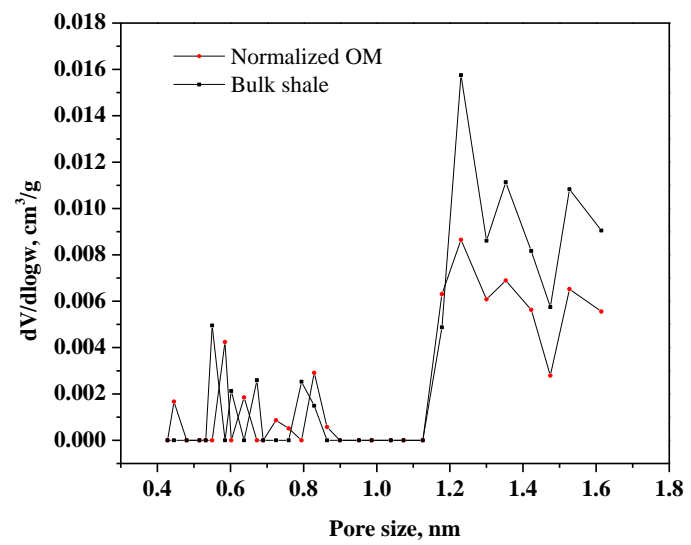

(b) Sample 2

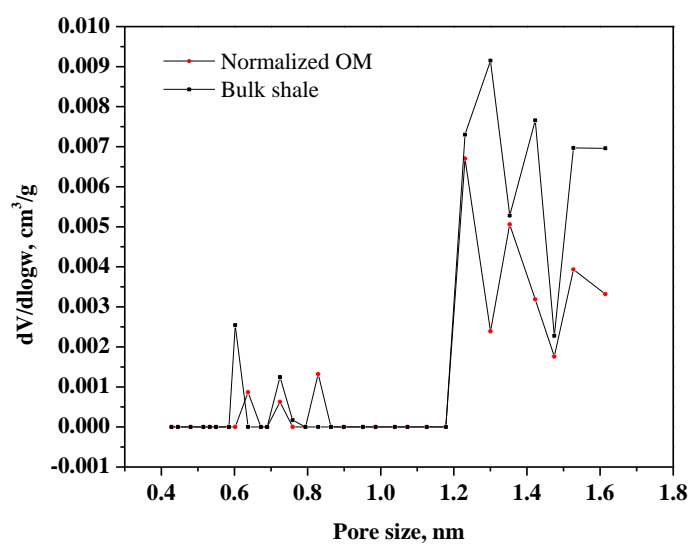

(d) Sample 4

Fig. 15. Micropore size distribution of the bulk shale and the weight-normalized isolated kerogen.

While comparing meso- and macropore size distributions of the bulk shale and weight normalized isolated kerogen samples (Fig. 16), it is observed that a notable gap in the data exists between the pore size distributions of these two sets of samples when pore sizes are smaller than 10nm. This is because the majority of pores from 2 to $10 \mathrm{~nm}$ in size are hosted within the minerals. Accordingly, 
when the pore sizes become larger than 30nm, the PSD curves from these two-different types of sample specimens nearly overlap and show similar characteristics. Therefore, it can be said that isolated kerogen contributes to pores larger than 30nm in size in Sample 2 and Sample 4. Regarding Sample 3, isolated kerogen and minerals both have pore sizes larger than $20 \mathrm{~nm}$. In Sample 1, when pore sizes are larger than $20 \mathrm{~nm}$, pore volumes from the isolated kerogen become larger than the pore volumes from the bulk shale samples. This could be due to the presence of clays or other minerals filling the pores in the organic matter. Therefore, when kerogen is isolated from the mineral matrix, removing the minerals can result in the exposure of such pores within the isolated kerogen.

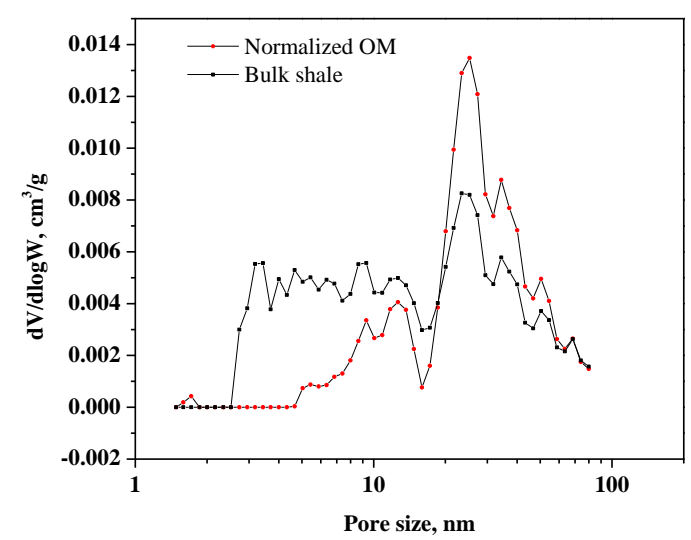

(a) Sample 1

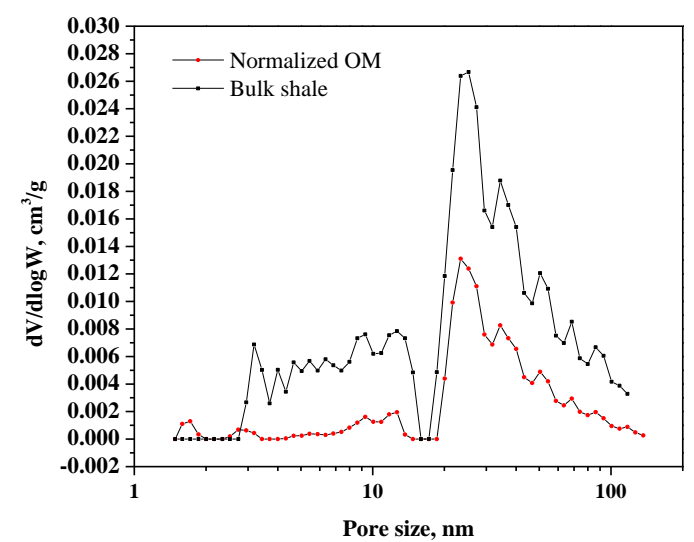

(c) Sample 3

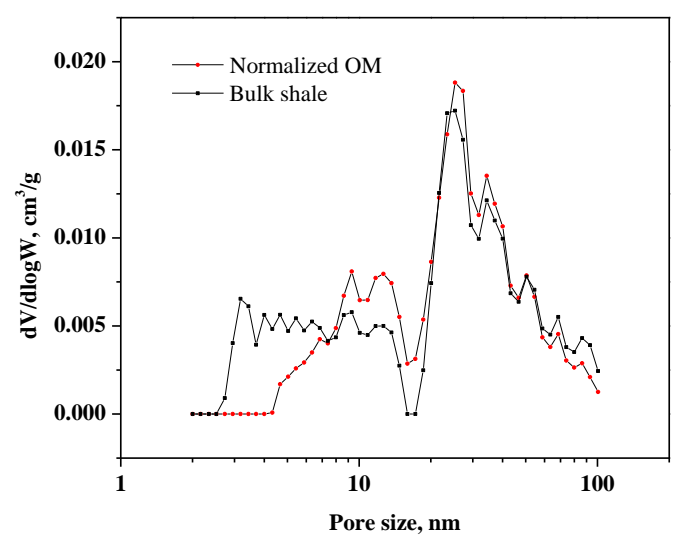

(b) Sample 2

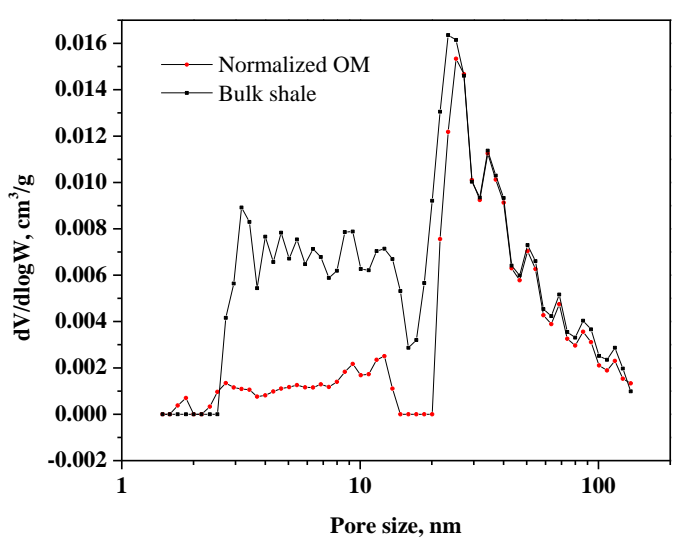

(d) Sample 4 
Fig. 16. Pore size distribution of bulk shale and the weight-normalized isolated kerogen (Mesoand macropores).

\section{Conclusions}

This study is a novel study of the pore structures of the Bakken shale and the isolated kerogen. In this study, the geochemical properties of the bulk shale were characterized while the pore structures of bulk shale and their corresponding isolated kerogen were quantified and compared. From the results, the following conclusions can be made:

1. $\mathrm{CO}_{2}$ gas adsorption of the samples showed that isolated kerogen has a larger micropore volume and larger micropore surface area compared to the bulk shale samples.

2. The larger BET surface area and pore volume derived from $\mathrm{N}_{2}$ adsorption depict that more mesoand macropores exist in the isolated kerogen than in the bulk shale samples.

3. Based on the PSD data deconvolution, pores in the bulk shale samples can be separated into six different groups while the pores of their corresponding isolated kerogen can be separated into 5 different clusters. It was found that both type of specimens of samples share similar pore clusters except cluster 1 in the bulk shale samples with a diameter of $4 \mathrm{~nm}$, which represents mineral pores.

4. Regarding the samples analyzed in this study, micropores are hosted mainly within the organic matter while the minerals host mainly mesopores with sizes ranging from 2 to $10 \mathrm{~nm}$.

\section{Acknowledgment}

The authors appreciate the support from China Scholarship Council (201406450029) and the four anonymous reviewers for their constructive comments, which improved the quality of the manuscript.

\section{Reference}

[1] Ji W, Song Y, Rui Z, Meng M, Huang H. Pore characterization of isolated organic matter from high matured gas shale reservoir. Int. J. Coal Geol. 2017;174: 31-40.

[2] Loucks RG, Reed RM, Ruppel SC, Jarvie DM. Morphology, genesis, and distribution of nanometerscale pores in siliceous mudstones of the Mississippian Barnett Shale. J. Sediment. Res. 2009; 79: 848-861.

[3] Loucks RG, Reed RM, Ruppel SC, Hammes U. Spectrum of pore types and networks in mudrocks and a descriptive classification for matrix related mudrock pores. AAPG Bull. 2012; 96: 1071-1098.

[4] Clarkson CR, Solano N, Bustin RM, Bustin AMM, Chalmers GRL, He L., et al. Pore structure characterization of North American shale gas reservoirs using USANS/SANS, gas adsorption, and mercury intrusion. Fuel. 2013; 103: 606. 
[5] Liu K, Ostadhassan M, Gentzis T, et al. Characterization of geochemical properties and microstructures of the Bakken Shale in North Dakota. Int. J. Coal Geol. 2017.

[6] Yang Y, Yao J, Wang C, Gao Y, Zhang Q. New pore space characterization method of shale matrix formation by considering organic and inorganic pores. J.Nat.Gas Sci.Eng. 2015. 27(P2) : 496-503.

[7] Milliken KL, Rudnicki M, Awwiller DN, Zhang T. Organic matter-hosted pore system, Marcellus Formation (Devonian), Pennsylvania. AAPG Bull. 2013; 97: 177-200.

[8] Löhr SC, Baruch ET, Hall PA, Kennedy MJ. Is organic pore development in gas shales influenced by the primary porosity and structure of thermally immature organic matter? Org. Geochem. 2015; 87: 119-132.

[9] Rouquerolb J, Avnir D, Fairbridge CW, et al. Recommendations for the characterization of porous solids (Technical Report). Pure Appl. Chem. 1994; 66(8): 1739-1758.

[10] Kuila U, Douglas K, et al. Nano-scale texture and porosity of organic matter and clay minerals in organic-rich mudrocks. Fuel. 2014; 135: 359-373.

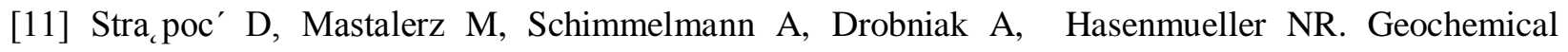
constraints on the origin and volume of gas in the New Albany Shale (Devonian-Mississippian), eastern Illinois Basin. AAPG Bull. 2010; 94: 1713-40.

[12] Lu X-C, Li F-C, Watson AT. Adsorption measurements in Devonian shales. Fuel. 1995; 74: 599-603.

[13] Zhang T, Ellis GS, Ruppel SC, Milliken K, Yang R. Effect of organic-matter type and thermal maturity on methane adsorption in shale-gas systems. Org. Geochem. 2012; 47:120-131.

[14] Ross DJK, Bustin MR. The importance of shale composition and pore structure upon gas storage potential of shale gas reservoirs. Mar. Pet. Geol. 2009; 26: 916-27.

[15] Vernik L, Liu X. Velocity anisotropy in shales: a petrophysical study. Geophysics. 1997; 62: 521-532.

[16] Prasad M, Mba KC, Mcevoy TE, Batzle ML. Maturity and impedance analysis of organic-rich shales. SPE Reserv. Eval. Eng. 2011; 14(05): 533-543.

[17] Xiong F, Jiang Z, Li P, Wang X, Bi B, et al. Pore structure of transitional shales in the Ordos Basin, NW China: Effects of composition on gas storage capacity. Fuel. 2017; 206: 504-515.

[18] Liu K, Ostadhassan M, Zhou J, et al. Nanoscale pore structure characterization of the Bakken shale in the USA. Fuel. 2017; 209: 567-578.

[19] Javadpour F. Nanopores and Apparent Permeability of GasFlow in Mudrocks (Shales and Siltstone). J. Can. Petro. Technol. 2009; 48 (8): 18-21.

[20] Javadpour F, Farshi MM, Amrein M. Atomic-Force Microscopy: A new Tool for Gas-Shale Characterization. SPE 161015.2012.

[21] Liu K, Ostadhassan M, \& Bubach B. Pore Structure Analysis by Using Atomic Force Microscopy. URTEC 2448210. 2016. 
[22] Li ZT, Liu DM, Cai YD, et al. Multi-scale quantitative characterization of 3-D pore-fracture networks in bituminous and anthracite coals using FIB-SEM tomography and X-ray mu-CT. Fuel. 2017; 209: 43-53.

[23] Su Y, Zha M, Ding XJ, et al. Pore type and pore size distribution of tight reservoirs in the Permian Lucaogou Formation of the Jimsar Sag, Junggar Basin, NW China. Mar. Pet. Geol. 2018; 89: 761774.

[24] Huang XF, and Zhao YP. Characterization of pore structure, gas adsorption, and spontaneous imbibition in shale gas reservoirs. J. Petrol. Sci. Eng. 2017; 159: 197-204.

[25] Wang L, Fu Y, Li J, et al. Mineral and pore structure characteristics of gas shale in Longmaxi Formation: a case study of Jiaoshiba gas field in the southern Sichuan Basin, China. Arab. J. Geosci. 2016; 9(19): 733.

[26] Shao X, Pang X, Li Q, et al. Pore structure and fractal characteristics of organic-rich shales: A case study of the lower Silurian Longmaxi shales in the Sichuan Basin, SW China. Mar. Pet. Geol. 2017; 80: 192-202.

[27] Gao ZY, and Hu QH. Estimating permeability using median pore-throat radius obtained from mercury intrusion porosimetry. J. Geophys. Eng. 2013; 10(2) : 025014.

[28] Pitman JK, Price LC, LeFever JA. Diagenesis and fracture development in the Bakken Formation, Williston Basin: Implications for reservoir quality in the middle member. U.S.G.S.Professional Paper 1653. 2001.

[29] Goklen KE, Stoecker TJ, \& Baddour RF. A method for the isolation of kerogen from green river oil shale. Industrial \& engineering chemistry product research and development. 1984; 23(2), 308-311.

[30] Romero-Sarmiento M-F, Pillot D, Letort G, Lamoureux-Var V , Beaumont V, Hu A.-Y, Garcia B. New Rock-Eval Method for Characterization of Unconventional Shale Resource Systems. Oil Gas Sci. Technol. 2015; 71: 1-9.

[31] Jarvie DM, Claxton B, Henk B, Breyer J. Oil and Shale Gas from Barnett Shale, Ft. Worth Basin, Texas. AAPG National Convention, Denver, CO. 3-6 June. 2001.

[32] Craddock PR, Le Doan TV, Bake K, Polyakov M, Charsky AM, Pomerantz AE. Evolution of kerogen and bitumen during thermal maturation via semi-open pyrolysis investigated by infrared spectroscopy. Energy \& Fuels. 2015; 29(4): 2197-2210.

[33] Do DD, Do HD. Pore characterization of carbonaceous materials by DFT and GCMC simulations: a review. Adsorpt. Sci. Technol. 2003; 21(5): 389-423.

[34] Amankwah KAG, and Schwarz JA. A modified approach for estimating pseudo-vapor pressures in the application of the Dubinin-Astakhov equation. Carbon. 1995; 33: 1313-1319. 
[35] Fan L, and Ziegler T. Nonlocal density functional theory as a practical tool in calculations on transition states and activation energies. Applications to elementary reaction steps in organic chemistry. J. Am. Chem. Soc. 1992; 114: 10890-10897.

[36] Liu K, Ostadhassan M, Zou J, Gentzis T, Rezaee R, Bubach B, \& Carvajal-Ortiz, H. Multifractal analysis of gas adsorption isotherms for pore structure characterization of the Bakken Shale. FUEL. 2018; 219(1), 296-311.

[37] Ferreiro JP, Miranda JGV, and Vázquez EV. Multifractal analysis of soil porosity based on mercury injection and nitrogen adsorption. Vadose Zone J. 2010; 9, 325-335.

[38] Feder J.. Fractals. Plenum Press, New York. 1988

[39] Halsey TC, Hensen MH, Kadanoff LP, et al. Fractal measures and their singularities: the characterization of strange sets. Phys. R. A. 1986; 33(2): 1141-1151.

[40] Chhabra A, and Jensen RV. Direct Determination of the $f(\alpha)$ singularity spectrum. Phys. Rev. Lett. 1989; 62: 1327.

[41] Mroczkowska-Szerszeń M, Ziemianin K, Brzuszek P, Matyasik I, \& Jankowski L. The organic matter type in the shale rock samples assessed by FTIR-ATR analyses. Nafta-Gaz. 2015; 71(6): 361-369.

[42] Chen Y, Zou C, Mastalerz M, Hu S, Gasaway C, \& Tao X. Applications of micro-Fourier transform infrared spectroscopy (FTIR) in the geological sciences-A review. Int. J. Mol. Sci. 2015; 16(12):30223-30250.

[43] Chen Y, Furmann A, Mastalerz M, \& Schimmelmann A. Quantitative analysis of shales by KBr-FTIR and micro-FTIR. Fuel. 2014; 116: 538-549.

[44] Sing KS, Everett DH, Haul RAW, Moscou L, Pierotti RA, Rouquerol J, Siemieniewsha T. Reporting physisorption data for gas/solid systems with special reference to the determination of surface area and porosity. Pure Appl. Chem. 1985; 57 (4): 603e619.

[45] Ulm FJ, Vandamme M, Bobko C, et al. Statistical indentation techniques for hydrated nanocomposites: concrete, bone, and shale. J. Am. Ceram. Soc. 2007; 90(9): 2677-2692.

[46] Sorelli L, Constantinides G, Ulm F-J. Toutlemonde F. The nano-mechanical signature of ultra high performance concrete by statistical nanoindentation techniques. Cem. Concr. Res. 2008; 38(12): $1447-1456$.

[47] Costa EVL, Nogueira RA. Fractal, multifractal and lacunarity analysis applied in retinal regions of diabetic patients with and without nonproliferative diabetic retinopathy. Fractal Geometry and Nonlinear Analysis in Medicine and Biology. 2015; 1(3): 112-119. 